\title{
Monoamines Inhibit GABAergic Neurons in Ventrolateral Preoptic Area That Make Direct Synaptic Connections to Hypothalamic Arousal Neurons
}

\author{
ㄷuki C. Saito, ${ }^{1,2 *}$ Takashi Maejima, ${ }^{2 \star}$ Mitsuhiro Nishitani, ${ }^{2}$ Emi Hasegawa, ${ }^{1,2}$ Yuchio Yanagawa, ${ }^{3}$ Michihiro Mieda, ${ }^{2}$ \\ and $\odot$ Takeshi Sakurai ${ }^{1,2,4}$ \\ ${ }^{1}$ International Institute for Integrative Sleep Medicine, University of Tsukuba, Tsukuba, Ibaraki 305-8575, Japan, ${ }^{2}$ Department of Integrative \\ Neurophysiology, Faculty of Medicine, Kanazawa University, Kanazawa 920-8640, Japan, ${ }^{3}$ Department of Genetic and Behavioral Neuroscience, Gunma \\ University Graduate School of Medicine, Maebashi, Gunma 371-8511, Japan, and ${ }^{4}$ Life Science Center for Tsukuba Advanced Research Alliance, University \\ of Tsukuba, Tsukuba, Ibaraki 305-8575, Japan
}

The hypothalamus plays an important role in the regulation of sleep/wakefulness states. While the ventrolateral preoptic nucleus (VLPO) plays a critical role in the initiation and maintenance of sleep, the lateral posterior part of the hypothalamus contains neuronal populations implicated in maintenance of arousal, including orexin-producing neurons (orexin neurons) in the lateral hypothalamic area (LHA) and histaminergic neurons in the tuberomammillary nucleus (TMN). During a search for neurons that make direct synaptic contact with histidine decarboxylase-positive (HDC+), histaminergic neurons (HDC neurons) in the TMN and orexin neurons in the LHA of male mice, we found that these arousal-related neurons are heavily innervated by GABAergic neurons in the preoptic area including the VLPO. We further characterized GABAergic neurons electrophysiologically in the VLPO (GABA ${ }^{\text {VLPO }}$ neurons) that make direct synaptic contact with these hypothalamic arousal-related neurons. These neurons (GABA ${ }^{\mathrm{VLPO} \rightarrow \mathrm{HDC}}$ or GABA ${ }^{\mathrm{VLPO} \rightarrow \text { orexin }}$ neurons) were both potently inhibited by noradrenaline and serotonin, showing typical electrophysiological characteristics of sleep-promoting neurons in the VLPO. This work provides direct evidence of monosynaptic connectivity between GABA ${ }^{\text {VLPO }}$ neurons and hypothalamic arousal neurons and identifies the effects of monoamines on these neuronal pathways.

Key words: histamine; noradrenaline; orexin; sleep; tracing; wakefulness

Significance Statement

Rabies-virus-mediated tracing of input neurons of two hypothalamic arousal-related neuron populations, histaminergic and orexinergic neurons, showed that they receive similar distributions of input neurons in a variety of brain areas, with rich innervation by GABAergic neurons in the preoptic area, including the ventrolateral preoptic area (VLPO), a region known to play an important role in the initiation and maintenance of sleep. Electrophysiological experiments found that GABAergic neurons in the VLPO (GABA ${ }^{\mathrm{VLPO}}$ neurons) that make direct input to orexin or histaminergic neurons are potently inhibited by noradrenaline and serotonin, suggesting that these monoamines disinhibit histamine and orexin neurons. This work demonstrated functional and structural interactions between $\mathrm{GABA}^{\mathrm{VLPO}}$ neurons and hypothalamic arousal-related neurons.

\section{Introduction}

Sleep/wakefulness states have been thought to be mainly regulated by two processes, the biological clock and "sleep load" or

Received Oct. 1, 2017; revised May 6, 2018; accepted June 11, 2018.

Author contributions: T.S. designed research; Y.C.S., T.M., E.H., and T.S. performed research; Y.Y. and T.S. contributed unpublished reagents/analytic tools; Y.C.S., T.M., M.N., M.M., and T.S. analyzed data; Y.C.S., T.M., and T.S. wrote the paper.

This work was supported by a KAKENHI Grant-in-Aid for Scientific Research on Innovative Areas ("Adaptive Circuit Shift" Grant JP15H01425 to T.S.), a Japan Society for the Promotion of Science (JSPS) KAKENHI Grant-in-Aid for Scientific Research (B; Grant JP 15 H03122 to T.S.), a KAKENHI Grant-in-Aid for Exploratory Research (Grant JP 15K12768 to T.S.), a KAKENHI Grant-in-Aid for Scientific Research on Innovative Areas ("Willdynamics" Grant "sleep pressure," an mechanism that is unknown but believed to accumulate during wakefulness and dissipate during sleep (Bor-

16H06401 to T.S.), a JSPS KAKENHI Grant-in-Aid for Scientific Research (C; Grant JP15K01832 to T.M.), a Grant-in-Aid for Young Scientists (B; Grant 16K21057 to Y.C.S.), the Merck Investigator Studies Program (Grant 54843 to T.S.), and a GlaxoSmithKline Japan Research Grant (T.M.). We thank Drs. Edward M. Callaway and Fumitaka Osakada for providing B7GG, BHK-EnvARGCD, and HEK293-TVA cell lines; Naoshige Uchida for providing PAAV-CAG-FLEX-RG and pAAV-EF1a-FLEX-TVA-mCherry; Kenji Sakimura for providing Gad67-Cre mice; Jun Tanimura and Rin Maeda for excellent technical assistance; and Wendy Gray for reading the manuscript.

The authors declare no competing financial interests.

*Y.C.S. and T.M. contributed equally to this work.

Correspondence should be addressed to Dr. Takeshi Sakurai, Faculty of Medicine/WPI-IIIS, University of Tsukuba, Tsukuba, Ibaraki 305-857, Japan. E-mail: sakurai.takeshi.g@u.tsukuba.ac.jp. 
bély, 1982). Accumulation of sleep pressure is postulated to inhibit arousal centers through activation of sleep-promoting neurons (Sherin et al., 1998; Gallopin et al., 2000; Steininger et al., 2001; Chou et al., 2002; Saper et al., 2010). Many studies have suggested that the ventrolateral preoptic area (VLPO) plays an important role in promotion of sleep by inhibiting several arousal-promoting neurons by GABAergic inhibitory projections (Sherin et al., 1998; Steininger et al., 2001; Saper et al., 2010; Chung et al., 2017). Some populations of VLPO neurons fire during sleep, but not during wakefulness (Sherin et al., 1996), and lesioning of the VLPO causes insomnia ( $\mathrm{Lu}$ et al., 2000). Although VLPO neurons were shown to send innervations to regions that contain neurons implicated in regulation of sleep/ wakefulness states, including the tuberomammillary nucleus (TMN) (Saper et al., 2010; Chung et al., 2017), the precise connectivities among these neuronal populations have not been shown clearly at a cellular level.

Here, focusing on populations of hypothalamic neurons that are critically implicated in arousal regulation, histidine decarboxylase-positive (HDC + ) histaminergic neurons (HDC neurons) in the TMN and neurons that produce orexin $\mathrm{A}$ and orexin B (hypocretin-1 and hypocretin-2) (orexin neurons) in the lateral hypothalamic area (LHA), we analyzed the architecture and function of hypothalamic circuits that link neuronal populations implicated in sleep/wakefulness regulation. By recombinant rabies-virus-mediated trans-synaptic retrograde tracing in the mouse brain (Wickersham et al., 2007), we identified input neurons of HDC and orexin neurons in broad areas of the brain, including many GABAergic neurons in the preoptic area (POA). The VLPO contains substantial numbers of GABAergic input cells for both orexin and HDC neurons (GABA VLPO $\rightarrow$ orexin and GABA ${ }^{\mathrm{VLPO} \rightarrow \mathrm{HDC}}$ neurons) and electrophysiological studies showed that serotonin (5-HT) and noradrenaline (NA) potently inhibited these GABAergic neurons, suggesting that HDC and orexin neurons are disinhibited by these monoamines through connections with GABA ${ }^{\text {VLPO }}$ neurons.

This study revealed functional and structural interactions between GABA VLPO and lateroposterior hypothalamic arousalregulated neurons and suggests that NA and 5-HT might affect these arousal neurons by regulating GABA ${ }^{\text {VLPO }}$ neurons, implicating these connections as playing an important role in arousal regulation.

\section{Materials and Methods}

Plasmids. pcDNA-SADB19L (catalog \#32632), pcDNA-SADB19G (cata$\log$ \#32633), pcDNA-SADB19N (catalog \#32630), pcDNA-SADB19P (catalog \#32631), pSADdeltaG-GFP-F2 (catalog \#32635), and pSADdeltaG$m$ Cherry (catalog \#32636) were from Addgene. pAAV-EF1a-FLEX-TVA$m$ Cherry and $p A A V$-CAG-FLEX-RG (Watabe-Uchida et al., 2012) were provided by Dr. N. Uchida (Harvard University). pAAV-CAG-FLEX (Frt)-ChR2-eYFP was generated by swapping the TVA-mCherry cassette of $p A A V$-CAG-FLEX (Frt)-TVA-mCherry (provided by Dr. Miyamichi, The University of Tokyo) with ChR2-eYFP.

Animals. All experimental procedures involving animals were approved by the Animal Experiment and Use Committees of the Kanazawa University and the University of Tsukuba, and were thus in accordance with NIH guidelines. Orexin-Cre and Orexin-eGFP transgenic mice were reported previously (Yamanaka et al., 2003; Matsuki et al., 2009). Gad67Cre mice, in which the Cre gene was knocked in the Gad67 allele, were described previously (Wu et al., 2011; Saito et al., 2013). Hdc-Cre mice (Tg(Hdc-cre)IM1Gsat/Mmcd) were from GENSAT. vGAT-ires-Cre mice were from The Jackson Laboratory (stock \#016962). Genotyping of these genetically modified mice was performed by PCR of tail DNA. Gad67-GFPAneo mice (Tamamaki et al., 2003) were used to obtain Orexin-Cre;Gad67-GFPAneo mice and Hdc-Cre;Gad67-GFPAneo mice. These lines were bred with wild-type C57BL/6J mice $>10$ times and maintained. To express channelrhodopsin-2 (ChR-2) or hM3Dq in serotonergic neurons in the dorsal raphe nucleus (DRN), we used SERTCre or ePet-Cre mice, which have a C57B/6J background (The Jackson Laboratory stock \#012712), respectively.

Viruses. We used AAV with the FLEX switch system (Atasoy et al., 2008) to express designated genes only in Cre recombinase-expressing neurons. AAVs were produced using a triple transfection, helper-free method using a previously described protocol (Sasaki et al., 2011). The final purified viruses were aliquoted and stored at $-80^{\circ} \mathrm{C}$. Recombinant rabies vectors were produced by a procedure described previously (Osakada and Callaway, 2013). Titers were $4.2 \times 10^{8}$ and $7.0 \times 10^{8}$ infectious units/ml for $S A D \Delta G-G F P(E n v A)$ and $S A D \Delta G-m C h e r r y$ $(E n v A)$, respectively. All AAV serotypes used in this study were AAV10. The titers of recombinant AAV vectors were determined by quantitative PCR: $A A V_{10}-E F 1 \alpha$-FLEX (loxP)-ChR2-EYFP; $3.7 \times 10^{13} ; A A V_{10}-C A G-$ FLEX (Frt)-TVA-mCherry, $4 \times 10^{13} ; A A V_{10}$-CAG-FLEX (Frt)-RG $1 \times$ $10^{13}$ genome copies/ml. CAV2-FLEX (loxP)-Flp virus was obtained from BioCampus Montpellier.

Virus injection. To express RG and TVA in HDC neurons, $1 \mu \mathrm{l}$ of AAV mixture carrying RG and TVA and $0.3 \mu \mathrm{l}$ of $S A D \Delta G-G F P(E n v A)$ or $S A D \Delta G-m C h e r r y(E n v A)$ were injected into the TMN of $H d c$-Cre mice (9-13 weeks old) at a site $2.2 \mathrm{~mm}$ posterior, $0.8 \mathrm{~mm}$ right, and $-5.5 \mathrm{~mm}$ ventral relative to the bregma. To express TVA and RG in orexin neurons, male Orexin-Cre mice (10-12 weeks old) were anesthetized with sodium pentobarbital $(0.5 \mathrm{mg} / \mathrm{kg}$, i.p.) and positioned in a stereotaxic frame. Four holes were drilled in the skull of each mouse at sites $-1.4 \mathrm{~mm}$ posterior, $\pm 0.9 \mathrm{~mm}$ lateral, and $-5.5 \mathrm{~mm}$ ventral; and $-1.8 \mathrm{~mm}$ posterior, $\pm 0.9 \mathrm{~mm}$ lateral, and $-5.7 \mathrm{~mm}$ ventral relative to the bregma (4 injection sites per mouse). Then, $0.5 \mu \mathrm{l}$ of purified AAV $\left(A A V_{10}-C A G-\right.$ FLEX (Frt)-TVA-mCherry and $A A V_{10}$-CAG-FLEX (Frt)-RG) was delivered to each site over a 10 min period using a Hamilton needle syringe (33 $\mathrm{Ga})$. After $5 \mathrm{~min}$ of rest, the needles were removed. Fourteen days later, $S A D \Delta G-G F P(E n v A)$ or $S A D \Delta G-m C h e r r y(E n v A)$ was injected with the same procedure. To express ChR2 or hM3Dq in DRN serotonergic neurons, we injected $1 \mu \mathrm{l}$ of $A A V_{10}-D I O-h C h R 2(H 134 R)-E Y F P$ (Wu et al., 2011) or $A A V_{10}-E F 1 \alpha-F L E X-h M 3 D q-m C h e r r y$, respectively, into the DRN of male SERT-Cre mice or ePet-Cre mice (4-5 weeks old) at a site $4.2 \mathrm{~mm}$ posterior, $\pm 0.0 \mathrm{~mm}$ lateral, and $-3.5 \mathrm{~mm}$ ventral relative to the bregma.

Histological analysis. For detecting input neurons, GFP+ or mCherry+ neurons were observed in coronal and sagittal sections throughout the brain by a single examiner using a fluorescence microscope (Keyence BZ-X710) or a confocal laser microscope (Leica SP8). Cells were counted on both sides of the brain in every third consecutive $30 \mu \mathrm{m}$ section. Brain regions were determined using the mouse brain map by Franklin and Paxinos (Franklin and Paxinos, 2001). Immunohistochemical staining was performed using the following antibodies: rabbit anti-HDC (Progen), rabbit anti-cFos (Millipore), biotinylated goat anti-rabbit IgG (Vector Laboratories), NeutrAvidin-Alexa Fluor 350 conjugate (Invitrogen), guinea pig anti-orexin (in-house), goat antipro-melanin-concentrating hormone (anti-pro-MCH; C-20; (Santa Cruz Biotechnology), rat anti-GFP (Nakarai), mouse anti-tryptophan hydroxylase (anti-TPH; Sigma-Aldrich), goat anti-mCherry (SICGEN), rabbit anti-AVP (Millipore), rabbit anti-CRH (Abcam), and Alexa Fluor 488-, Alexa Fluor 594-, or Alexa Fluor 647-conjugated secondary antibodies (goat anti-guinea pig IgG, donkey anti-goat IgG, donkey antirabbit IgG, and goat anti-rat IgG; Invitrogen). We examined the activity of orexin neurons by counting Fos+/Orexin + cells in the LHA. Fos+ cells in the LHA were counted (cells per area) in coronal sections from -1.7 to -2.06 from the bregma. Cells were counted on both sides of these brain regions.

Electrophysiological studies. For electrophysiological analysis of $\mathrm{VLPO}^{\mathrm{GABA}}$ input neurons, we used Hdc-Cre;Gad-GFP or orexin-Cre; Gad-GFP $>$ Hdc-Cre;Gad67-GFP $\Delta$ Neo or orexin-Cre;Gad67-GFP $\Delta$ Neo 
mice labeled with $S A D \Delta G-m C h e r r y(E n v A)$ as described above. For analysis of serotonergic input to orexin neurons, we used SERT-Cre;OrexinGFP mice injected with $A A V_{10}-E F 1 \alpha-F L E X$ (loxP)-ChR2-EYFP in the DRN. Coronal brain slices ( $250 \mu \mathrm{m}$ thick) including the LHA were prepared as described previously (Yamanaka et al., 2003). Under an upright fluorescence microscope (Olympus), we identified fluorescing neurons visually in the designated areas. During recordings, the slices were continuously perfused with artificial CSF containing the following (mM): 125 $\mathrm{NaCl}, 2.5 \mathrm{KCl}, 2 \mathrm{CaCl}_{2}, 1 \mathrm{MgSO}_{4}, 26 \mathrm{NaHCO}_{3}, 1.25 \mathrm{NaH}_{2} \mathrm{PO}_{4}$, and 10 D-glucose equilibrated with $95 \% \mathrm{O}_{2}$ and $5 \% \mathrm{CO}_{2}$ and added bicuculline $(10 \mu \mathrm{M}), \mathrm{CNQX}(10 \mu \mathrm{M})$, and D-AP5 $(20 \mu \mathrm{M})$ to block fast inhibitory and excitatory synaptic transmission. Whole-cell patch-clamp recordings were made at $30^{\circ} \mathrm{C}$ with borosilicate glass electrodes (5-6 M $\Omega$ ) filled with an internal solution containing the following $(\mathrm{mm})$ : $125 \mathrm{~K}$-gluconate, 4 $\mathrm{NaCl}, 10$ HEPES, 0.2 EGTA, $2 \mathrm{MgCl}_{2}$, 4 ATP, 0.4 GTP, and 10 phosphocreatine, $\mathrm{pH} 7.3$, adjusted with $\mathrm{KOH}$. A combination of an EPC10/2 amplifier and Patchmaster software (HEKA) was used to control membrane voltage, data acquisition, and the triggering of light pulse irradiation with an LED device (KSL-70; Rapp OptoElectronic) at a wavelength of $470 \mathrm{~nm}$ (maximum: $8 \mathrm{~mW} / \mathrm{mm}^{2}$ ).

DREADD experiments. Two weeks after expressing hM3Dq in serotonergic neurons in the DRN in ePet-Cre mice, we injected clozapine- $N$ oxide $(\mathrm{CNO})(2 \mathrm{mg} / \mathrm{kg})$ or saline intraperitoneally at Zeitgeber time 5 (ZT5). Ninety minutes later, mice were fixed and subjected to histologi$\mathrm{cal}$ analysis.

Statistical analysis. Data are presented as mean \pm SEM and were analyzed by paired $t$ test or independent $t$ test in combination with tests for normality and equality of variance (GraphPad Prism 6).

\section{Results}

\section{Neurons that make direct synaptic contact with histidine decarboxylase neurons}

We used BAC-transgenic Hdc-Cre mice (Tg(Hdc-cre)IM1Gsat/ Mmcd) (Gong et al., 2003) to depict neurons that make direct synaptic contact with HDC neurons by rabies-mediated retrograde tracing (Wickersham et al., 2007). First, we injected Creactivatable AAV vectors expressing TVA and RG (Atasoy et al., 2008) into the TMN of $\mathrm{Hdc}$-Cre mice (Fig. 1A) to express TVA and RG specifically in HDC neurons. Two weeks later, we injected $S A D \Delta G-G F P(E n v A)$ in the same region. These mice were killed 4-7 $\mathrm{d}$ after the injection and subjected to histological analyses (Fig. 1A).

We detected neurons with red fluorescence in the TMN due to specific expression of TVA-mCherry in these cells (Fig. 1B). Immunostaining showed that $96.4 \pm 1.6 \%$ of TVA-mCherry + neurons were also positive for HDC-like immunoreactivity (mean \pm SD, $n=1014$ TVA-mCherry+ neurons, $n=4$ mice), suggesting that TVA was expressed specifically in histaminergic neurons (Fig. $1 B$ ). Near the injection site, $52.8 \pm 26.2 \%$ of these cells were also positive for GFP (mean $\pm \mathrm{SD}, n=978$ TVA-mCherry- and HDC-double-positive neurons in TMN, $n=4$ mice), suggesting that they were primarily infected with $S A D \Delta G-G F P(E n v A)$ (starter cells).

Figure $1 C$ shows a typical example of the distribution of input neurons found in a representative mouse. In the rodent hypothalamus, HDC neurons are grouped into five clusters, E1-E5, each of which sends overlapping widespread projections throughout the brain (Ericson et al., 1987; Inagaki et al., 1990; Moriwaki et al., 2015). In our histological examinations, most starter neurons were found in the ventrolateral and ventromedial parts of the posterior hypothalamus, corresponding approximately to the E1 and E2 clusters, which have been shown to be involved in the regulation of arousal (Sakai et al., 2010; Umehara et al., 2012; Yu et al., 2015) (Fig. 1C,D). We found that the num- bers of starter neurons and input neurons throughout the brain were positively correlated (Fig. 1E).

We detected many GFP + but mCherry $-\left(\mathrm{GFP}^{+} ; \mathrm{mCherry}^{-}\right)$ neurons (input neurons) in broad areas within the hypothalamus (Fig. $1 F$ ), suggesting that HDC neurons receive abundant intrahypothalamic input. The POA, LHA, dorsomedial hypothalamus $(\mathrm{DMH})$, ventromedial hypothalamus $(\mathrm{VMH})$, paraventricular thalamic nucleus (PVN), medial tuberal nucleus (MTu), arcuate nucleus (Arc), and posterior hypothalamus $(\mathrm{PH})$ contained particularly large numbers of input neurons (Fig. $1 F, G$ ). Immunohistochemical studies showed that some of these GFP + neurons in the LHA were positive for orexin-like immunoreactivity $(9.3 \pm$ $3.4 \%$ of GFP + neurons; $n=472$ from 4 mice, mean \pm SD) and melanin concentrating hormone $(\mathrm{MCH})$-like immunoreactivity ( $10.9 \pm 1.7 \%$ of GFP + neurons, $n=672$ from 4 mice, mean \pm SD; Fig. $1 H)$, indicating that these peptidergic neurons in the hypothalamus have direct synaptic connectivity with HDC neurons in the TMN.

We also detected positive neurons in various brain regions outside of the hypothalamus, including the medial and lateral septum (MS and LS), nucleus accumbens (NAC), bed nucleus of the stria terminalis (BNST), ventral pallidum (VP), periaqueductal gray (PAG) of the midbrain and pons, anterior, ventral, and dorsal tegmental nuclei (A/VTg and DTg), and raphe magnus and obscurus nuclei (RMg/Ob) (Fig. $1 F, G$ ).

\section{Neurons that send direct synaptic input to orexin neurons}

Because orexin neurons send abundant axonal projections to the TMN, which expresses abundantly OX2R, a subtype of orexin receptor that plays a major role in regulating arousal (Nambu et al., 1999; Date et al., 2000; Mieda et al., 2011), histaminergic neurons in the TMN have been recognized as an important player in regulation of arousal as the downstream component of the orexin system. Our retrograde tracing study of HDC neurons confirmed that orexin neurons make direct synaptic input to HDC neurons (Fig. 1H). We mapped further upstream neurons that make direct monosynaptic input to orexin neurons by recombinant rabies virus $S A D \Delta G-G F P(E n v A)$-mediated tracing applied to the LHA of Orexin-Cre transgenic mice, in which Cre recombinase is exclusively expressed by orexin neurons (Fig. 2A) (Matsuki et al., 2009).

In the LHA, mCherry was specifically observed in orexin+ neurons (Fig. $2 B$ ). Most mCherry+ neurons were also positive for GFP (starter cells) (Fig. $2 B$ ). We also detected many singly labeled $\left(\mathrm{GFP}^{+} ; \mathrm{mCherry}^{-}\right)$neurons (input neurons) in broad areas of the hypothalamus (Fig. 2C,D), suggesting the existence of abundant intrahypothalamic input to orexin neurons. The POA, AHA, DMH, LHA, PVN, and PH contained especially large numbers of input neurons. Double-staining studies suggested that some populations of labeled neurons in the PVN are positive for corticotropin-releasing hormone $(\mathrm{CRH})$ or arginine vasopressin $(\mathrm{AVP})$ (Fig. $2 E, 18.1 \pm 6.5 \%, n=3$, mean \pm SEM, and $6.1 \pm$ $1.0 \%, n=4$, mean $\pm \mathrm{SEM}$ ) of GFP + neurons were positive for $\mathrm{CRH}$ and AVP, respectively), suggesting that these stress response-related neurons might play a role in activation of orexin neurons given that previous electrophysiological studies suggested that CRH and AVP activate orexin neurons in vitro (Winsky-Sommerer et al., 2004; Tsunematsu et al., 2008).

Outside of the hypothalamus, we detected positive neurons in various brain regions, including the LS, NAC, BNST, VP, PAG, and median raphe (MnR) (Fig. 2C,D). Another group performed mapping of direct inputs to orexin neurons using the SAD vector and orexin-Cre mice, which were provided by us (González et al., 
A

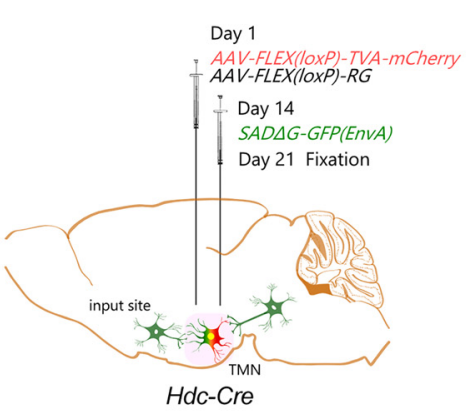

C

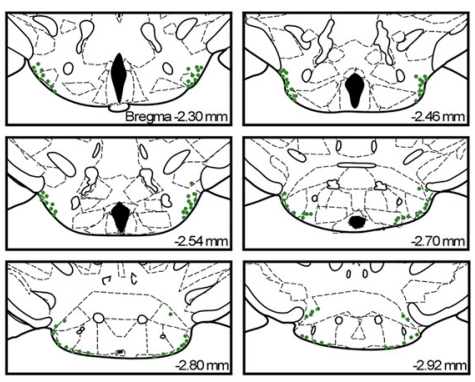

B

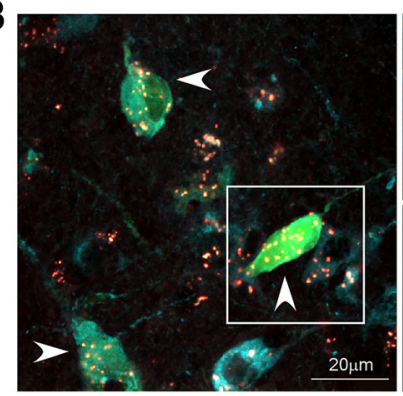

D

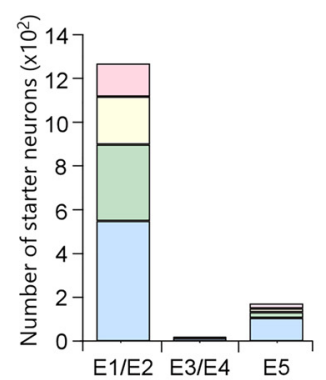

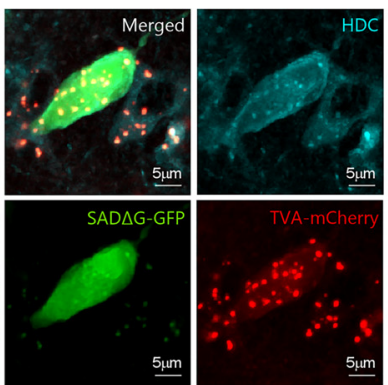

E

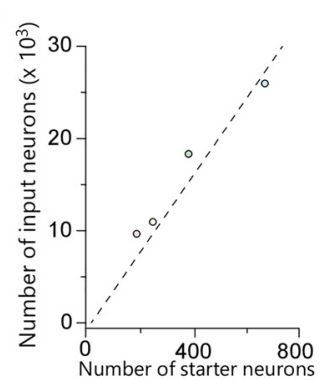

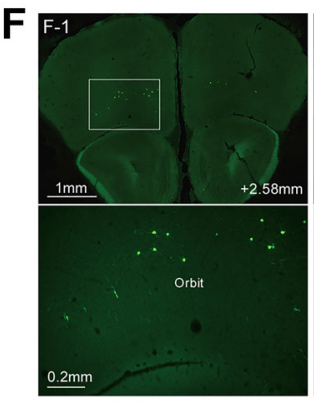
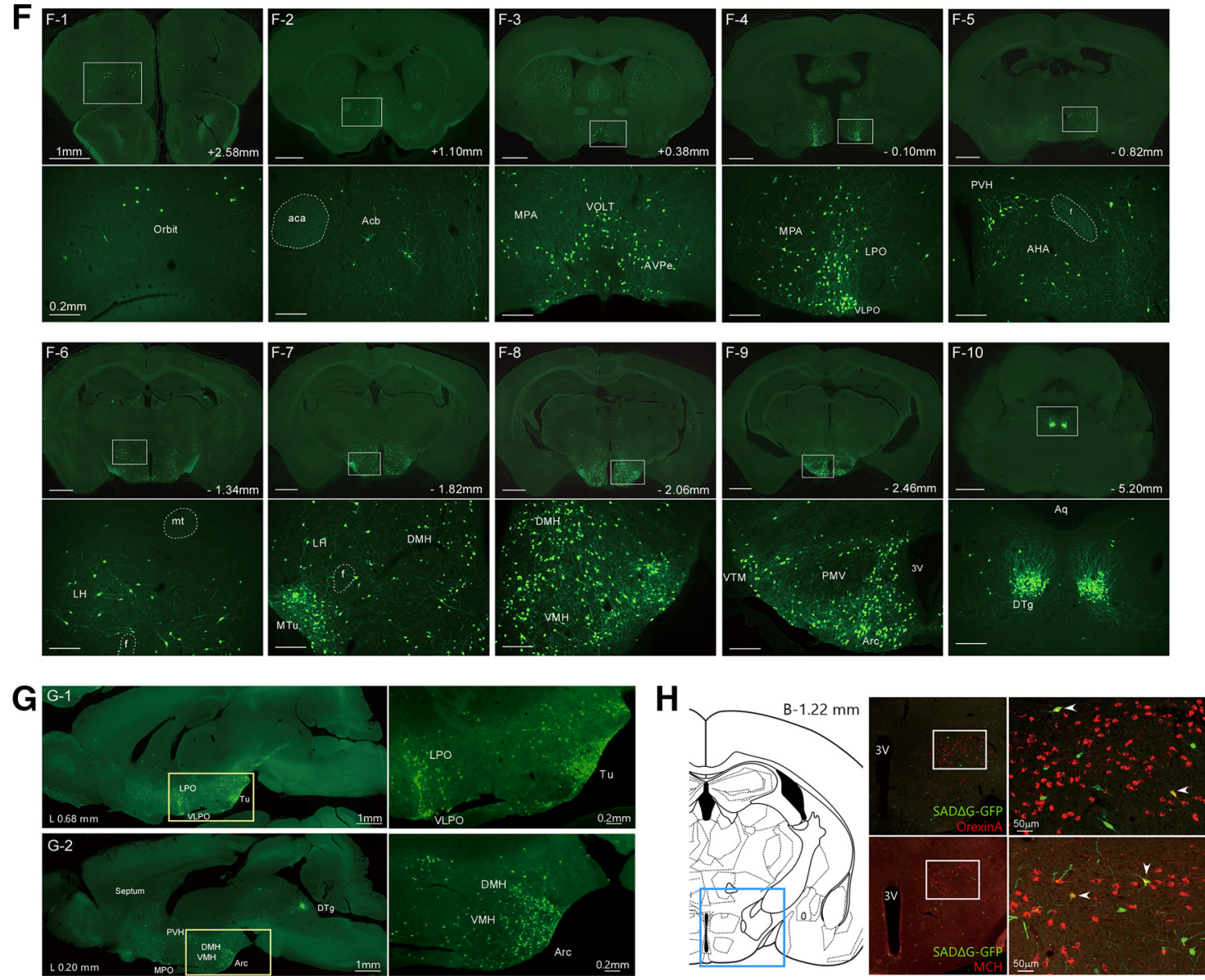

Figure 1. Visualization of monosynaptic input to HDC neurons. A, Schematic drawing of procedure for rabies-based trans-synaptic retrograde tracing. We injected AAV10-FLEX-TVA-mCherry and AAV10-FLEX-RG stereotaxically into the TMN of transgenic mice expressing Cre in HDC neurons (Hdc-Cre). After 14d, SAD G-GFP(EnvA) was injected into the same area and the brains were analyzed after 4-7 d. B, Starter cells were identified based on coexpression of TVA-mCherry and GFP. Double-positive neurons were found only in the injected area and were also HDC + . C, Schematic depiction of distribution of starter neurons observed in the TMN of a representative mouse. $\boldsymbol{D}$, Number of starter neurons in each sample is shown. Most starter neurons were found in the E1 and E2 histaminergic clusters in the TMN (four sampled mice). $\boldsymbol{E}$, Although the number of labeled neurons varied among animals due to different infection efficiency in each sample, the number of labeled neurons was almost proportional to the number of starter neurons. $\boldsymbol{F}$, Distribution of input neurons in coronal sections of representative mouse brain. $\boldsymbol{G}$, Distribution of input neurons in sagittal sections of representative mouse brain. $\boldsymbol{H}$, Double-fluorescent images of LHA (left) stained for orexin (red) and SAD-GFP (green) or MCH (red) and SAD-GFP (green). Arrowheads indicate double-positive neurons in each magnified view (right). 
A

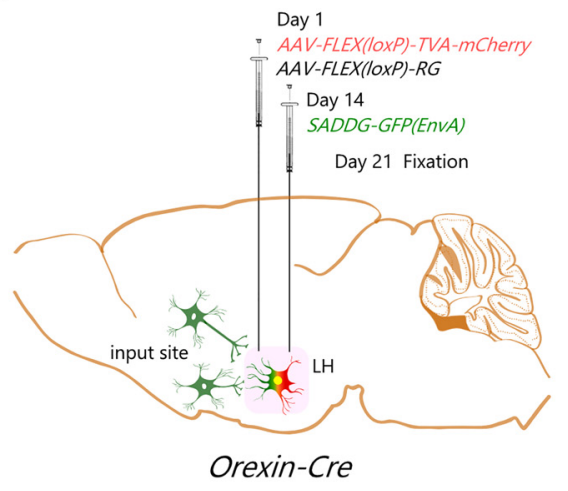

B

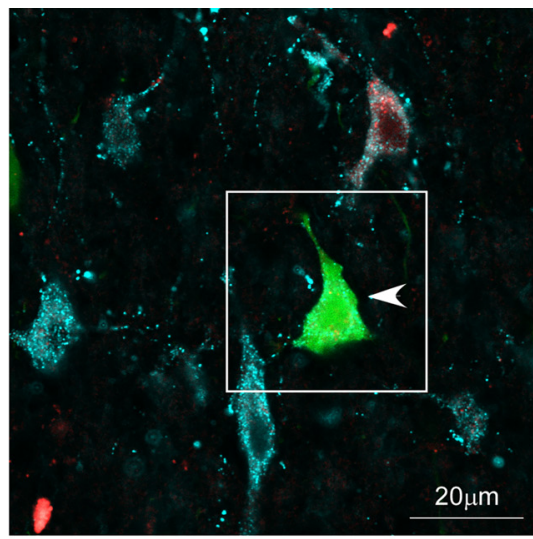

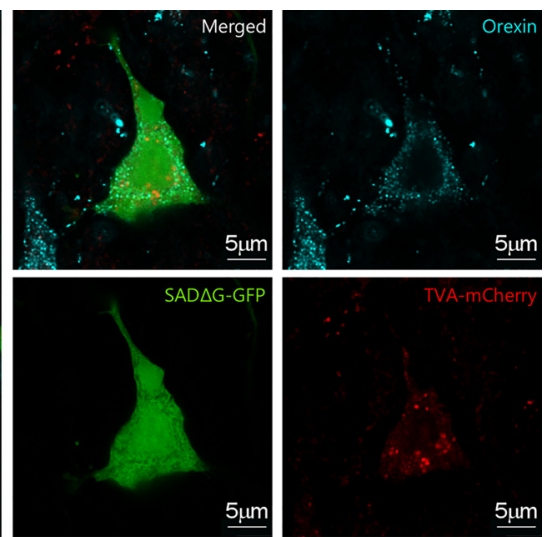
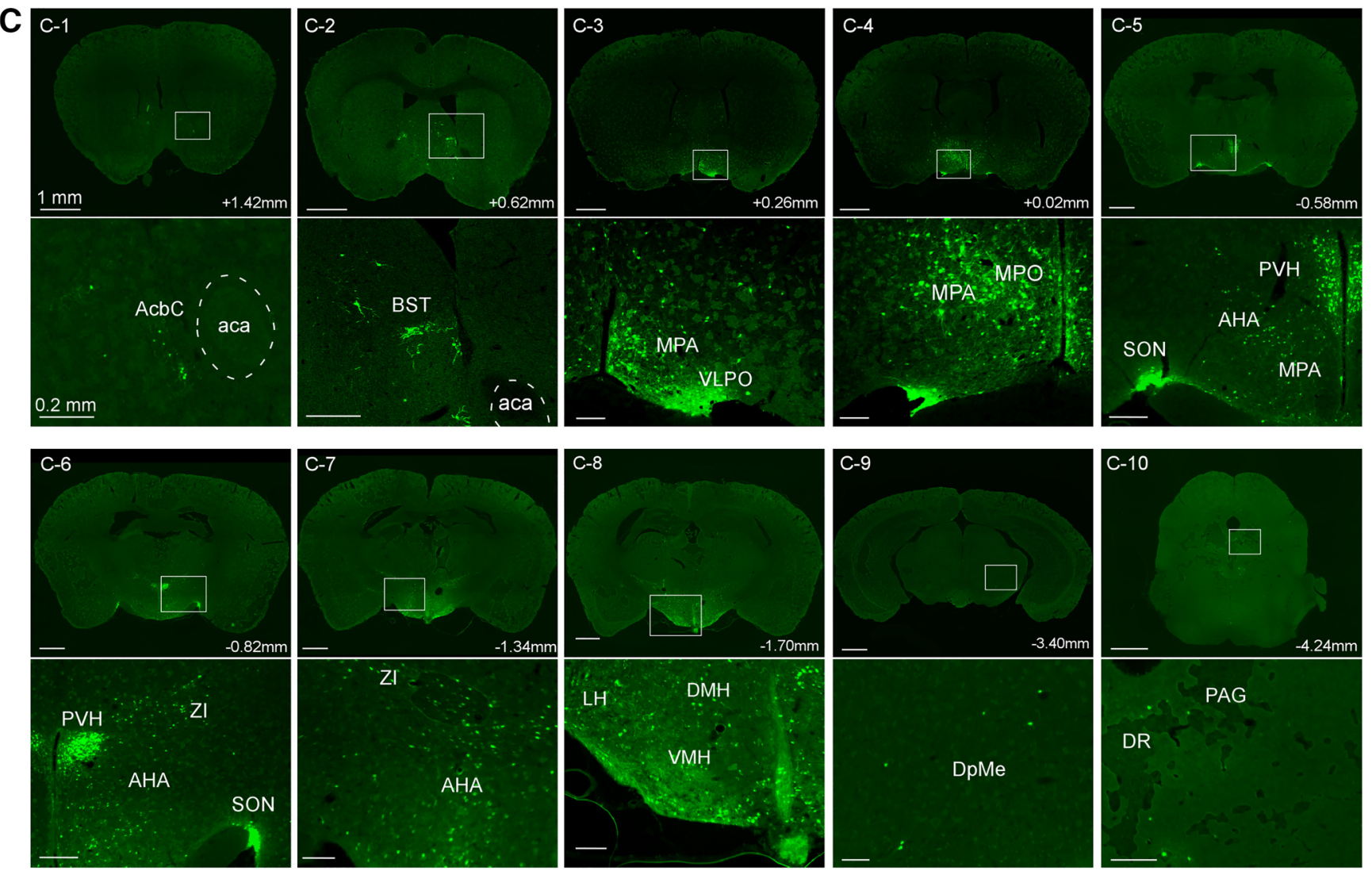

D

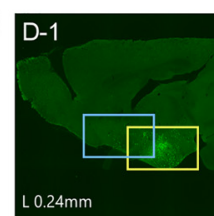

$1 \mathrm{~mm} 0.2 \mathrm{~mm}$

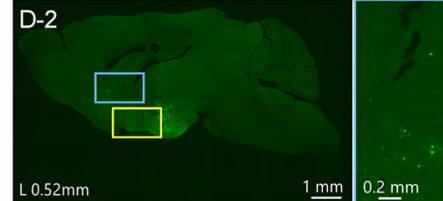

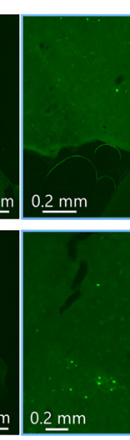

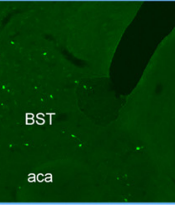

E

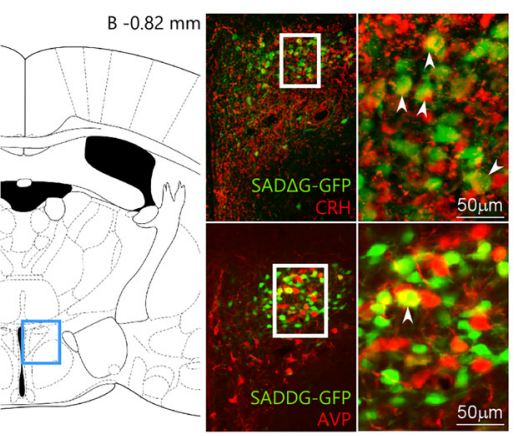

Figure 2. Visualization of monosynaptic input to orexin neurons. $A$, Schematic representation of the procedure. We injected AAV10-FLEX-TVA-mCherry and AAV10-FLEX-RG stereotaxically into the LHA of transgenic mice expressing Cre in orexin neurons (Orexin-Cre). After $14 \mathrm{~d}$, SAD $\Delta$ G-GFP(EnvA) was injected into the LHA and the brains were analyzed $4-7 \mathrm{~d}$ after injection. B, Starter cells were identified by coexpression of TVA-mCherry and EGFP. C, Distribution of input neurons in coronal sections of the brain of a representative mouse. D, Distribution of input neurons in sagittal sections of the brain of a representative mouse. E, Double-fluorescent images of PVH stained with CRH (red) and SAD-GFP (green) or AVP (red) and SAD-GFP (green). Left, Representative drawing of sections shown in right panels. 

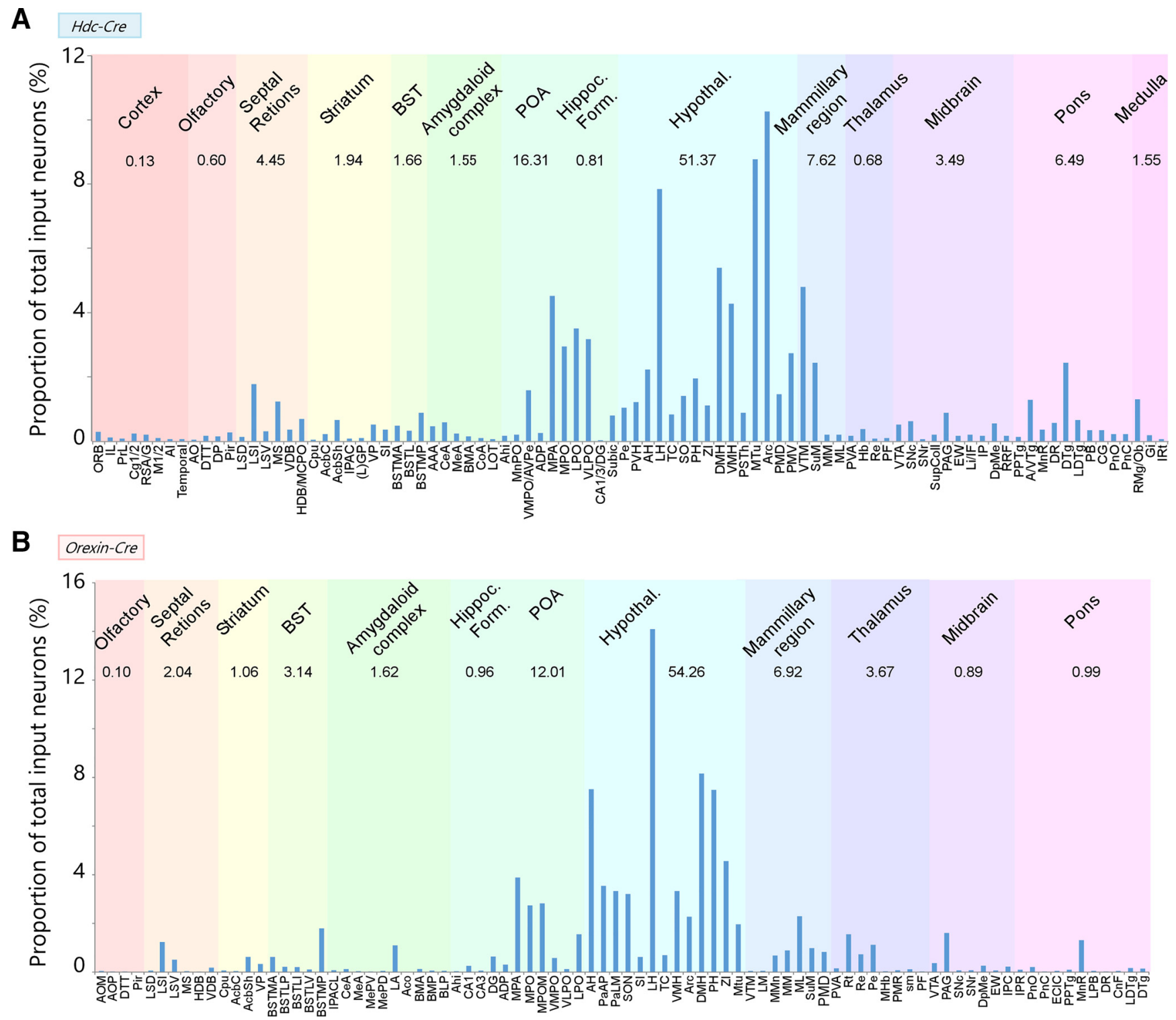

Figure 3. Graphic representation of distribution of input neurons of $\mathrm{HDC}$ neurons $(\boldsymbol{A})$ and orexin neurons $(\boldsymbol{B})$ throughout the brain. Values are mean of four and six samples, respectively.

2016a). They obtained virtually the same results as ours. We further examined the chemical identities of input cells.

\section{Input by GABAergic neurons in preoptic area to orexin and histamine neurons}

As shown in Figure 3, $A$ and $B$, which is a graphic representation of the distributions of input neurons for HDC and orexin neurons throughout the brain, we identified many input neurons in the $\mathrm{POA}$, a region implicated in sleep regulation. We next investigated whether these input neurons are GABAergic because GABAergic inhibition of arousal-related neurons by POA neurons is thought to play an important role in sleep regulation (Chung et al., 2017). To make identification of GABAergic neurons easier, we used Gad67-GFP( $\Delta$ neo $)$ mice in which GABAergic neurons are labeled by GFP (Tamamaki et al., 2003). We used $S A D \Delta G-m C h e r r y(E n v A)$, which carries mCherry instead of GFP. After injecting AAV-FLEX-TVA-mCherry and AAV-FLEX-RG into the TMN or LHA of Gad67-GFP( $\Delta$ neo);Hdc-Cre mice and Gad67-GFP $\Delta$ Neo;Orexin-Cre mice, respectively, we injected $S A D \Delta G-m C h e r r y(E n v A)$ into the LHA or TMN of these mice
(Fig. 4A). Input neurons were identified by expression of mCherry, whereas GABAergic neurons showed GFP fluorescence driven by the transgene. We identified GFP- and mCherrydouble-positive neurons as GABAergic input neurons to orexin or HDC neurons. We found that $43.6 \pm 3.3 \%, 47.8 \pm 3.0 \%$, and $30.1 \pm 3.4 \%$ of input neurons of HDC neurons in the lateral preoptic area (LPO), medial preoptic area (MPA), and medial preoptic nucleus (MPO) were GABAergic, respectively $(n=4)$, while $47.6 \pm 4.1 \%, 63.5 \pm 9.9 \%$ and $27.2 \pm 1.1 \%$ of input neurons of orexin neurons in the LPO, MPA, and MPO were GABAergic, respectively ( $n=4$; Fig. $4 B-F)$.

The existence of direct synaptic input by GABA ${ }^{\mathrm{POA}}$ neurons to orexin neurons shown by this study is consistent with previous studies by us and from others showing that optogenetic activation of GABAergic fibers arising from POA potently inhibited orexin neurons and HDC neurons in vitro (Saito et al., 2013; Chung et al., 2017). To further confirm the connectivity among $\mathrm{GABA}^{\mathrm{POA}}$, orexin, and HDC neurons, we performed anterograde tracing of $\mathrm{GABA}^{\mathrm{POA}}$ neurons using ChR2-eYFP as an anterograde tracer. We injected a Cre-dependent CAV2 vector 
A
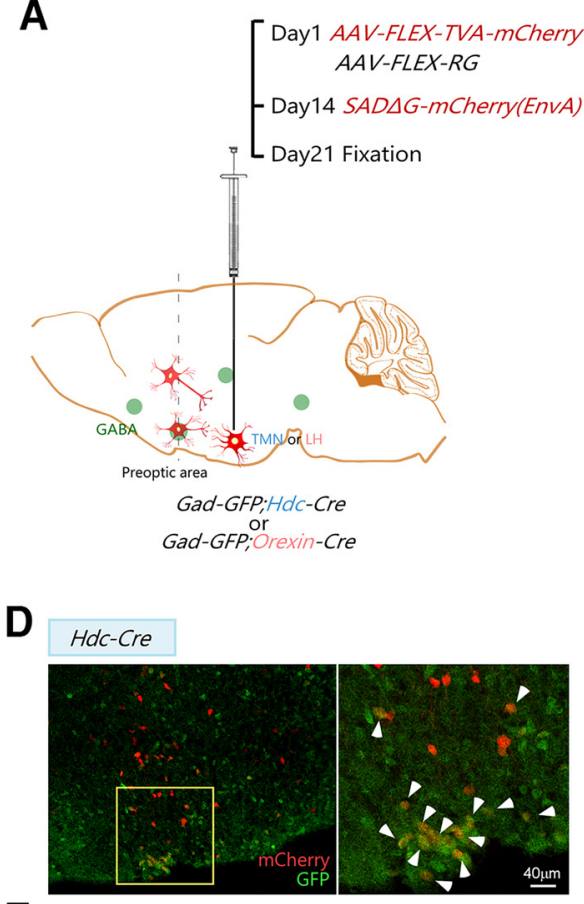

E

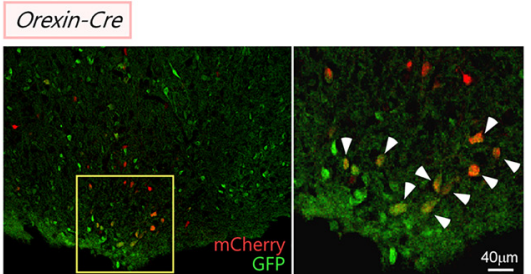

B
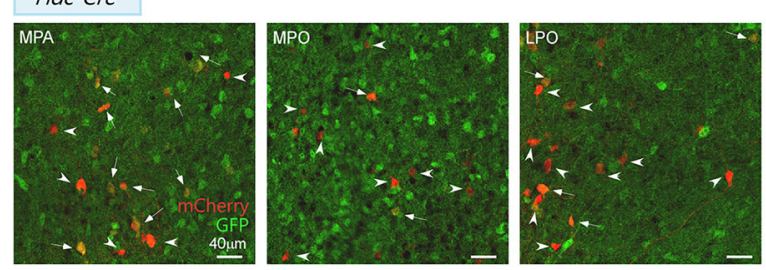

C
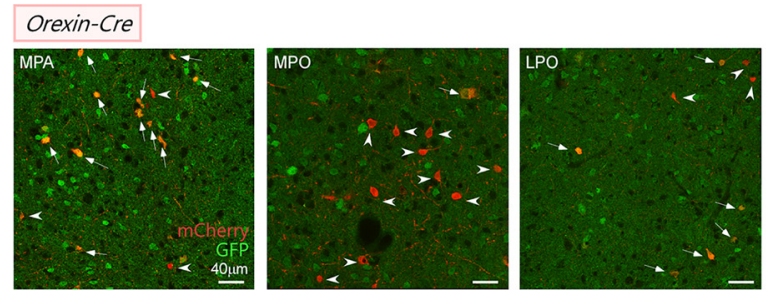

$\mathbf{F}$

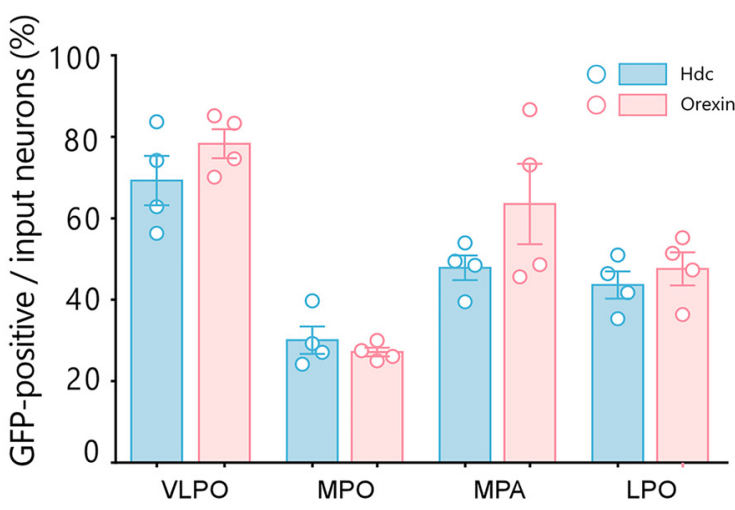

G

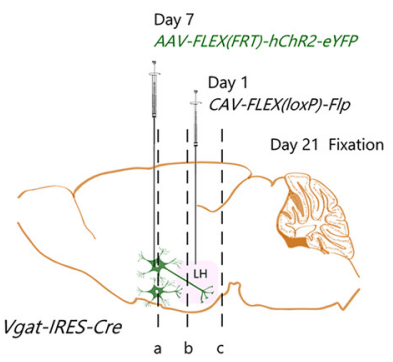

I

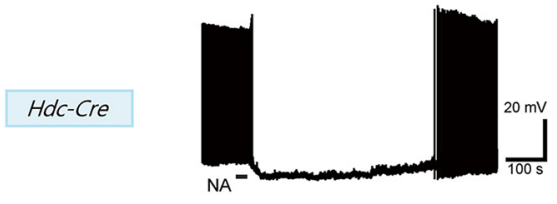

H

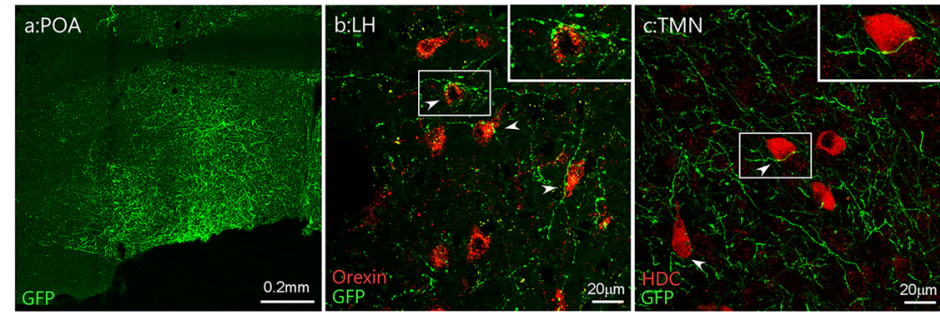

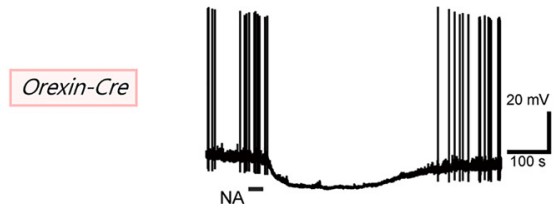
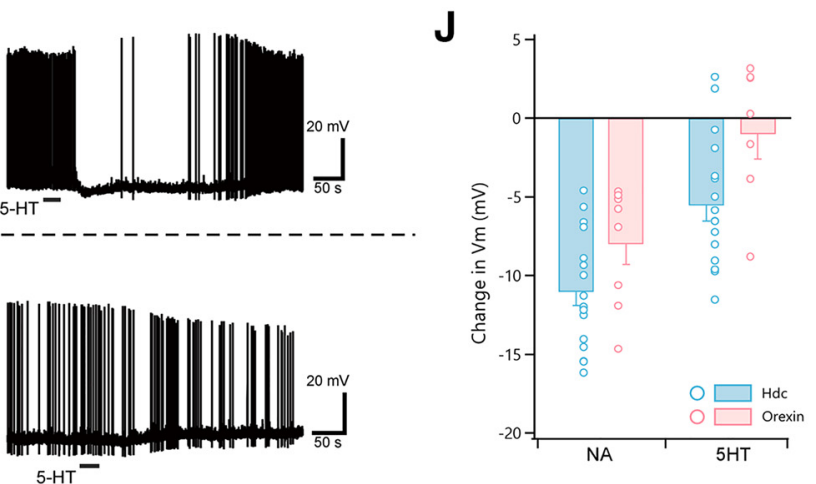

Figure 4. Visualization of GABAergic neurons in the POA, which make monosynaptic input to HDC and orexin neurons. $A$, Schematic representation of the procedure. We injected AAV10-FLEXTVA-mCherry and AAV10-FLEX-RG stereotaxically into the TMN of Gad67-GFP $\Delta$ Neo; Hdc-Cre or the LHA of Gad67-GFP $\Delta$ Neo;Orexin-Cre mice. After 14 d, SAD $\Delta$ G-mCherry(EnvA) was injected into the same areas and the brains were analyzed $4-7 \mathrm{~d}$ after injection. $\boldsymbol{B}$, Representative images of distribution of labeled cells in POA of Gad67-GFP $\Delta$ Neo;Hdc-Cre mice. $\boldsymbol{C}$, Representative image of distribution of labeled cells in POA of Gad67-GFP $\Delta$ Ne0;Orexin-Cre mice. Green, GFP. Red, SAD $G$-mCherry. D, GABAergic input neurons to HDC neurons in the VLPO. Right, High-power view of rectangular region in left panel. $\boldsymbol{E}$, GABAergic input neurons to orexin neurons in VLPO. Right, High-power view of rectangular region in the panel. $\boldsymbol{F}$, Percentages of double-positive GABAergic neurons among input neurons to HDC neurons or orexin neurons in designated POA areas. G, Analysis of axonal arborization pattern of GABA ${ }^{\text {VLPO } \rightarrow \text { LHA }}$ neurons. CAV2-FLEX (IoxP)FIp was injected into

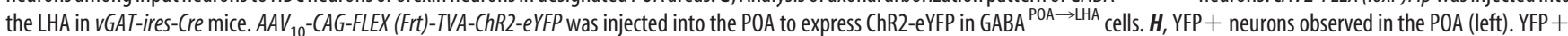
fibers make close appositions to orexin and HDC neurons (middle and right). $I$, Specimen responses of GABA VLPO $\rightarrow$ HDC neurons (top traces) and GABA ${ }^{\text {VLPO } \rightarrow \text { orexin }}$ neurons (bottom traces) to 30 s bath application of $100 \mu \mathrm{M}$ NA or $100 \mu \mathrm{M} 5-\mathrm{HT}$. J, Summary of changes in membrane potential of GABA VLPO $\rightarrow$ HDC neurons and GABA ${ }^{\text {VLPO } \rightarrow \text { orexin }}$ neurons induced by drugs. 
carrying flippase (Flp) recombinase (CAV2-FLEX (loxP) Flp) into the LHA in $v G A T$-ires-Cre mice. CAV2 infects axon terminals and is transported retrogradely to cell bodies, allowing us to express Flp specifically in Cre-expressing GABAergic neurons that send projections to the LHA. We then injected the Flpactivatable AAV vector $A A V_{10^{-}}$CAG-FLEX (Frt)-TVA-ChR2eYFP into the POA to express ChR2-eYFP in GABA ${ }^{\mathrm{POA} \rightarrow \mathrm{LHA}}$ cells (Fig. 4G). Two weeks later, LHA and TMN slices were prepared and subjected to histological analyses to determine whether eYFP+ fibers make appositions to orexin and HDC neurons, respectively. We found that many YFP+ fibers make close appositions to these cells, confirming that some populations of GA$\mathrm{BA}^{\mathrm{POA}}$ neurons send collateral axonal projections to both orexin and HDC neurons (Fig. 4H).

\section{$\mathrm{VLPO}^{\mathrm{GABA} \rightarrow \text { orexin }}$ and VLPO ${ }^{\mathrm{GABA} \rightarrow \mathrm{HDC}}$ neurons are inhibited by monoamines}

Within the POA, we detected many GABAergic input neurons in the VLPO by retrograde tracing of both orexin and HDC neurons (Fig. $4 A-H$ ). We found that $69.3 \pm 6.1 \%$ and $78.3 \pm 3.6 \%$ of input neurons for HDC and orexin neurons, respectively, in the VLPO were GABAergic (Fig. $4 F$ ). Because the VLPO is thought to play a key role in promoting sleep (Steininger et al., 2001; Saper et al., 2010), we characterized GABAergic neurons in the VLPO (GABA ${ }^{\text {VLPO }}$ neurons). Because c-Fos expression in the VLPO was shown to increase during sleep (Sherin et al., 1996), we initially tried to examine c-Fos expression in labeled VLPO cells after rebound sleep. However, we found that it was very challenging to stain c-Fos protein after SAD $\Delta \mathrm{G}$ infection, presumably due to dysfunction of these neurons induced by infection (data not shown). One of the criteria that identify sleep-active neurons in the VLPO is their inhibitory response to NA and 5-HT (Gallopin et al., 2000, 2005; Liu et al., 2010; Moore et al., 2012; Varin et al., 2015). Therefore, we next examined the effects of these monoamines on activities of VLPO GABAergic neurons labeled by retrograde tracing of HDC neurons or orexin

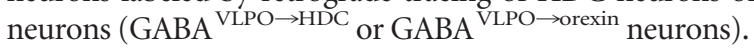

We performed whole-cell patch-clamp recordings from GABAergic input neurons in slice preparations labeled by $S A D \Delta G$ $m$ Cherry (EnvA) in Gad67-GFP( $\Delta$ neo);Hdc-Cre mice. Doublefluorescence-positive neurons $\left(\mathrm{GFP}^{+} ; \mathrm{mCherry}^{+}: \mathrm{GABA}^{\mathrm{VLPO} \rightarrow \mathrm{HDC}}\right.$ neurons; Fig. 4A) were subjected to recordings. We examined the effects of bath applications of NA and 5-HT (Fig. 4I,J) using relatively high concentrations of NA and 5-HT (100 $\mu \mathrm{M})$, based on the concentrations used in a previous study (Gallopin et al., 2000), to ensure identification of responsible cells and found that most GABA ${ }^{\mathrm{VLPO} \rightarrow \mathrm{HDC}}$ neurons were inhibited by these factors. In particular, NA $(100 \mu \mathrm{M})$ hyperpolarized all neurons tested. Approximately two-thirds of VLPO ${ }^{\text {GABA } \rightarrow \mathrm{HDC}}$ neurons were inhibited by 5 -HT $(100 \mu \mathrm{M})$ (Fig. $4 J)$.

We also tested the effects of these factors on GABA VLPO $\rightarrow$ orexin neurons in slice preparations labeled by $\mathrm{SAD} \Delta \mathrm{G}-\mathrm{mCherry}(\mathrm{EnvA})$ in Gad67-GFP( $\Delta$ neo $)$;orexin-Cre mice. Double-positive neurons $\left(\mathrm{GFP}^{+} ; \mathrm{mCherry}^{+}: \mathrm{GABA}^{\mathrm{VLPO} \rightarrow \text { orexin }}\right.$ neurons; Fig. $\left.4 A\right)$ comprised $78 \%$ of input neurons (mCherry + cells) in the VLPO region (Fig. $4 F)$. NA potently inhibited all GABA ${ }^{\mathrm{VLPO} \rightarrow \text { orexin }}$ cells (Fig. $\left.4 F, I, J\right)$. However, fewer VLPO ${ }^{\text {GABA } \rightarrow \text { orexin }}$ neurons were inhibited by $5-\mathrm{HT}$ compared with GABA ${ }^{\mathrm{VLPO} \rightarrow \mathrm{HDC}}$ neurons (Fig. 4J). Mean hyperpolarization evoked by 5-HT in GABA ${ }^{\mathrm{VLPO} \rightarrow \text { orexin }}$ neurons was smaller than that in GABA ${ }^{\mathrm{VLPO} \rightarrow \mathrm{HDC}}$ neurons, whereas there was no difference in NA effects between these neurons (Fig. $4 J$ ).

These observations suggest that NA and 5-HT disinhibit orexin neurons and histaminergic neurons through GABA ${ }^{\mathrm{VLPO}}$ neurons, although 5-HT showed a smaller effect on GABA VLPO $\rightarrow$ orexin neurons than on GABA ${ }^{\mathrm{VLPO} \rightarrow \mathrm{HDC}}$ neurons.

\section{Monoaminergic input to orexin neurons is not identified by rabies tracing}

Although our previous electrophysiological work suggested that orexin neurons are regulated by monoamines (Muraki et al., 2004; Yamanaka et al., 2006), SAD $\Delta$ G tracing did not detect any input neurons in any monoaminergic nuclei, such as the locus ceruleus, DRN, and TMN (Fig. 1). Therefore, we hypothesized that $\mathrm{SAD} \Delta \mathrm{G}$ is transported from postsynaptic neurons to presynaptic neurons only when synapses between these two components are classical, tight synapses. When neurons make loose synapses and use volume transmission, these neurons might not be depicted. Our previous study showed that orexin neurons abundantly express 5- $\mathrm{HT}_{1 \mathrm{~A}}$ receptors (Muraki et al., 2004), raising the possibility that orexin neurons are inhibited by the serotonergic system, although we did not find any positive cells in the DRN by retrograde tracing of orexin neurons. To examine the effect of serotonergic neurotransmission on orexin neuronal activity, we used ChR2 as an anterograde tracer and an optogenetic tool. We injected $A A V$-DIO-hChR2(H134R)-EYFP into the DRN of SERT-Cre mice (Figs. 5A). Double immunostaining with antiGFP and anti-TPH antibodies of brain slices prepared from these mice showed that $>90 \%$ of YFP + (ChR-YFP-expressing) neurons in the DRN also expressed TPH (92.8\%, $n=3$; Fig. 5B). We also observed ChR2-YFP+ fibers in the LHA that that made close apposition to orexin neurons in a single plane image under laser confocal microscopy, suggesting that 5-HT neurons in the DRN (5-HT ${ }^{\text {DRN }}$ neurons) send projections to the orexin field (Fig. $5 C$ ). These observations suggest a close anatomical connection between serotonergic axons arising from the DRN and orexin neurons. Because 5-HT is known to be diffusely released in a volume transmission manner and behaves as a neuromodulator rather than as a classical neurotransmitter (Agnati et al., 1995), the close apposition of serotonergic fibers to orexin neurons suggests functional and physiological interaction between $5-\mathrm{HT}^{\mathrm{DRN}}$ neurons and orexin neurons. To further confirm functional connectivity, we next performed whole-cell patch-clamp recordings from orexin neurons during optogenetic stimulation of ChR2eYFP-containing fibers in the LHA. We prepared acute LHA slices from SERT-Cre;orexin-GFP mice previously injected with $A A V$-DIO-hChR2(H134R)-EYFP into the DRN and made patchclamp recordings from GFP+ orexin neurons. We then stimulated the axons with LED light of $472 \mathrm{~nm}$ in a $90-\mu \mathrm{m}$-diameter window surrounding recorded orexin neurons. Under currentclamp mode, light flashes (10 ms width, 10 times at $10 \mathrm{~Hz}$ ) hyperpolarized and slowed the firing rate of these neurons (Fig. $5 D, E)$. The hyperpolarization of orexin neuron firing was almost completely abolished by a specific $5-\mathrm{HT}_{1 \mathrm{~A}}$ receptor antagonist, WAY100635 (30 $\mu \mathrm{M}$; Fig. 5D). We observed light-induced hyperpolarization $>0.3 \mathrm{mV}$ in 15 of 40 cells tested $(37.5 \%)$. These observations indicate that serotonergic axons originating from DRN neurons modulate orexin neurons via $5-\mathrm{HT}_{1 \mathrm{~A}}$ receptors.

These results clearly suggest that DRN serotonergic neurons send functional input to orexin neurons, although retrograde tracing with $\mathrm{SAD} \Delta \mathrm{G}$ did not elucidate input neurons in the DRN.

\section{Effect of excitation of serotonergic neurons in dorsal raphe on orexin neurons}

We found that optogenetic excitation of DRN serotonergic fibers in the LHA caused inhibition of orexin neurons (Fig. 5). However, we also found that GABA ${ }^{\text {VLPO } \rightarrow \text { orexin }}$ neurons are inhibited 
A

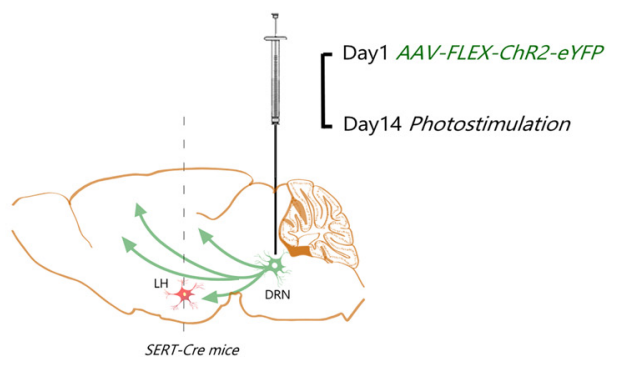

C
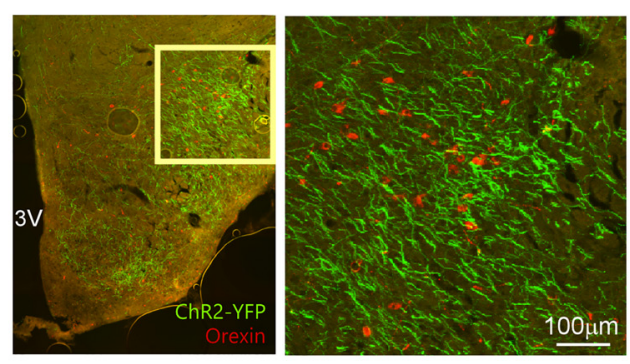

E
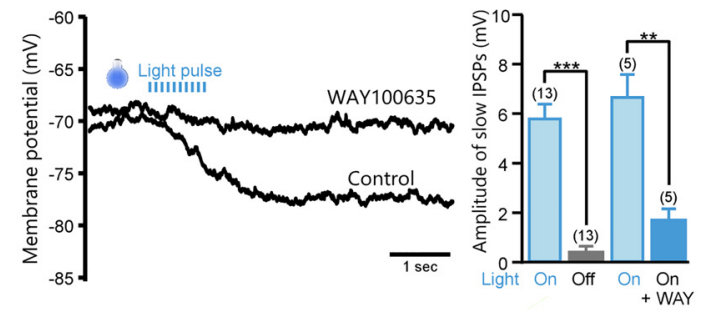

B
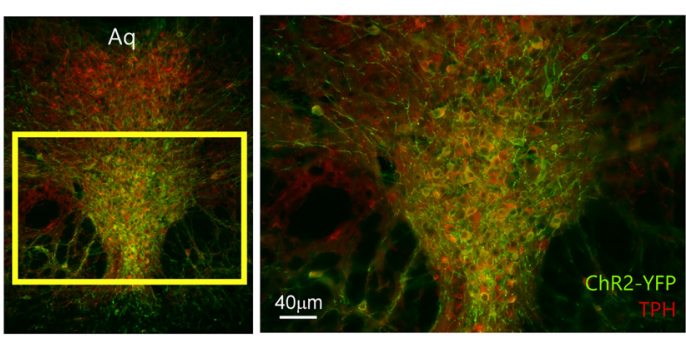

D

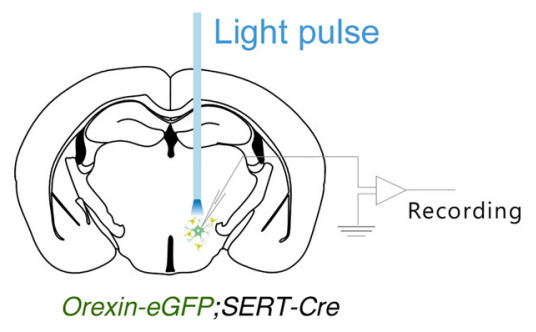

F
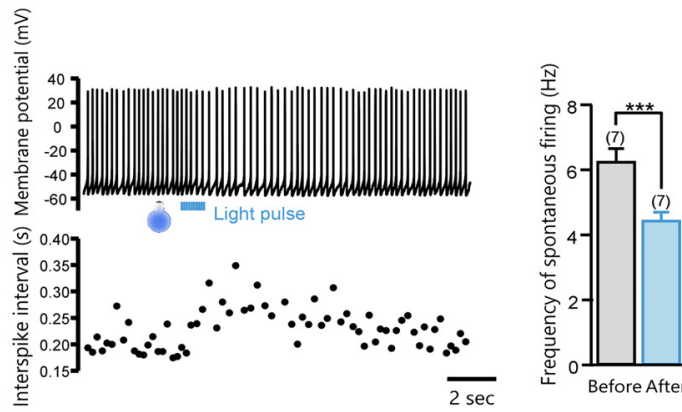

G
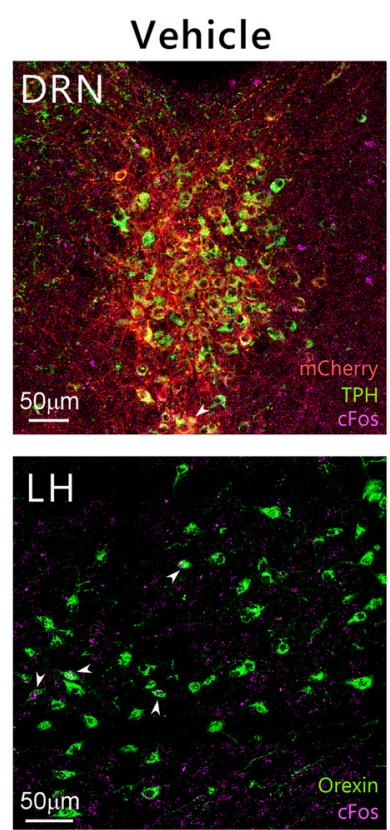

CNO
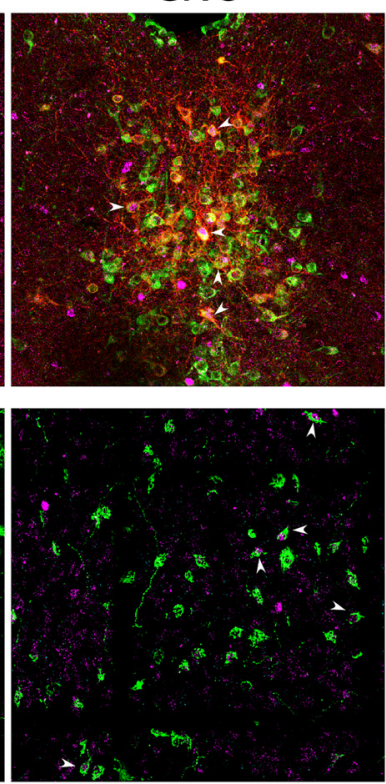

H

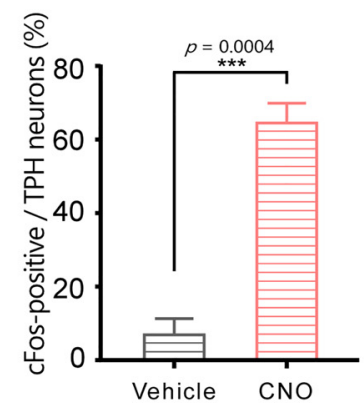

I

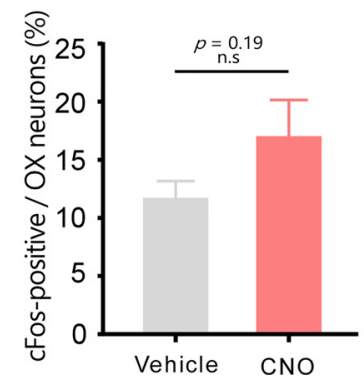

Figure 5. Orexin neurons are innervated by serotonergic fibers arising from the DRN. A, Schematic drawing of procedure for AAV-DI0-hChR2(H134R)-EYFP injection into the DRN of SERT-Cre mice. $B$, Representative image of DRN after injection of AAV. Left, Double-immunofluorescent image of DRN showing that most ChR2-YFP + neurons (green) are also positive for TPH-like immunoreactivity (red). Right, Higher-power view of rectangular region in left panel. C, ChR2-YFP + fibers make apposition to orexin neurons in LHA. Representative image of LHA slice stained with anti-orexin antibody (red). Right, High-power view of rectangular region in lower left panel. D, Schematic representation of procedure. We injected the same virus into DRN of (Figure legend continues.) 


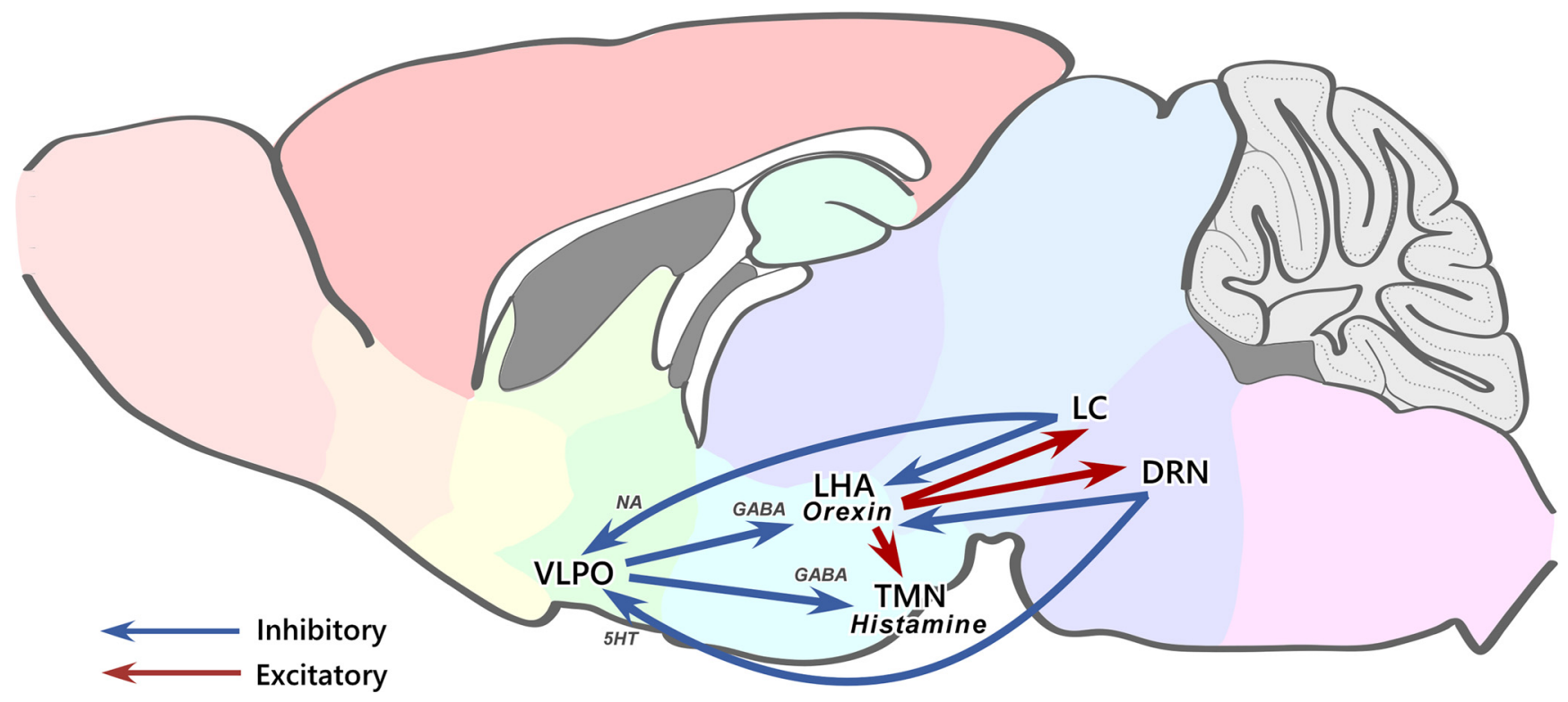

Figure 6. Connections among POA GABAergic neurons, oresin neurons, HDC neurons, and monoaminergic neurons.

by 5 -HT, suggesting that activation of serotonergic neurons disinhibits orexin neurons (Fig. 4). To elucidate the effect of serotonergic influence on the activity of orexin neurons in vivo, we examined the expression of Fos protein in orexin neurons after chemogenetic excitation of 5-HT ${ }^{\mathrm{DRN}}$ neurons. In this study, to induce activation of these cells, we used a DREADD using hM3Dq-mCherry, which was delivered by AAV (AAV-EF1 $\alpha$ DIO-hM3Dq-mCherry) into the DRN of ePet-Cre mice. In these mice, hM3Dq-mCherry was expressed in $98.53 \pm 0.55 \%$ of mCherry + cells were TPH $2+(n=7)$, confirming targeted expression of $\mathrm{hM} 3 \mathrm{Dq}$ in serotonin neurons.

We conducted DREADD experiments during the light period (ZT5), when serotonergic neurons are relatively silent. After intraperitoneal injection of CNO $(2 \mathrm{mg} / \mathrm{kg})$ to stimulate $5-\mathrm{HT}^{\mathrm{DRN}}$ neurons (Fig. 5G), mice were killed 90 min later and subjected to histological analysis. We found that $\mathrm{CNO}$ treatment increased Fos- and tryptophan hydroxylase (TPH)-double-positive neu-

$\leftarrow$

(Figure legend continued.) Orexin-eGFP;SERT-Cre mice. After $14 \mathrm{~d}$, brains were analyzed. $\boldsymbol{E}$, Photostimulation of serotonergic axons expressing ChR2-YFP induced membrane hyperpolarization mediated by the $5-\mathrm{HT}_{1 \mathrm{~A}}$ receptor in hypothalamic orexin neurons. Left, Slowly developing hyperpolarization induced by a light pulse train $(472 \mathrm{~nm}, 10 \mathrm{~ms}$ light pulses were applied 10 times at $10 \mathrm{~Hz}$; timing is indicated by lines). Hyperpolarization was abolished in the presence of a $5-\mathrm{HT}_{1 \mathrm{~A}}$ receptor antagonist, WAY-100635 $(30 \mu \mathrm{m})$. In this experiment, neurons underwent constant current injection to set the membrane potential at $\sim-70 \mathrm{mV}$. Right, Summary plots showing average hyperpolarization amplitude obtained in each condition (On; photostimulation, Off; no stimulation, On + WAY; photostimulation in presence of WAY-100635). Amplitude was calculated by subtraction of the averaged membrane potential measured $2-4 \mathrm{~s}$ after light application from that measured $0-1$ s before light. $\boldsymbol{F}$, Left top, Spontaneous action potential firing of orexin neurons was inhibited by the same light pulse train as shown in $\boldsymbol{E}$. Left bottom, Interspike intervals of action potentials shown at the top plotted along the time axis. Right, Summary plots showing average firing frequency measured $0-3 \mathrm{~s}$ before light (black) and $1-4$ s after light (gray). ${ }^{* *} p<0.01,{ }^{* * *} p<0.001$, paired $t$ test. Number of cells tested in each experiment is shown in parentheses. $\mathbf{G}$, Top, Coronal brain sections containing the DRN prepared from ePet-Cre mice with targeted injection of $A A V_{10}-E F 1 \alpha-D I 0-h M 3 D q-m C h e r r y$ in the DRN triple-stained with anti-Fos (magenta), anti-TPH (green), and anti-GFP (red) antibodies. Bottom, Coronal brain section containing the LHA stained with anti-Fos (red) and antiorexin (green) antibodies. Left, Control; right, CNO treatment. $\boldsymbol{H}$, Percentage of Fos- and TPH-double-positive neurons. $I$, Percentage of Fos- and orexin-double-positive neurons. Data are shown as means \pm SEM. ${ }^{* * *} p<0.001$, two-tailed Student's $t$ test. rons, suggesting that $\mathrm{CNO}$ activated $5-\mathrm{HT}^{\mathrm{DRN}}$ neurons. However, we repeatedly failed to detect obvious inhibition of orexin neurons. Rather, we found a tendency for an increase of Fos + orexin neurons in the $\mathrm{CNO}$-injected group compared with the control group ( $16.77 \pm 3.38$ and $11.47 \pm 1.71 \%$, respectively, $p=$ $0.019, n=4$ ), although this was not statistically significant. This observation suggests that the influence of activation of serotonergic neurons in the DRN on orexin neurons is minimal. The inhibition of $\mathrm{GABA}^{\mathrm{VLPO} \rightarrow \text { orexin }}$ neurons, shown by retrograde labeling (Fig. 2) as well as electrophysiological experiments (Fig. $4 G$ ), might counteract the direct inhibitory effect of the serotonergic projection.

\section{Discussion}

\section{Technical considerations}

Precise identification of neurons that send direct input to hypothalamic neurons implicated in arousal regulation, including HDC and orexin neurons, would provide important information to understand the mechanisms that control animals' sleep/wakefulness states. In this study, we mapped neuronal populations that make direct synaptic input to HDC and orexin neurons using SAD $\Delta$ G vectors (Wickersham et al., 2007; Wall et al., 2010; Miyamichi et al., 2011). We previously mapped upstream neuronal populations that send innervations to orexin neurons using transgenic mice in which orexin neurons expressed a recombinant retrograde tracer protein, tetanus toxin C-terminal fragment fused with GFP (IGFP-TTC; Sakurai et al., 2005). We postulate that this method depicts only a part of upstream neurons because the transfer efficiency of IGFP-TTC was so low that we had to use a high concentration of anti-GFP antibody and enhancement to detect the tracer. In addition, input neurons revealed by this method were not necessarily neurons that send direct synaptic input to orexin neurons because IGFP-TTC could be further transferred to second or higher-order upstream neurons (Maskos et al., 2002). When we compared these two studies, although abundant input from hypothalamic regions including the POA was similarly shown in both studies, TTC tracing showed more intense input from the amygdaloid regions, BNST, and brainstem regions including the raphe nuclei and laterodorsal/pedunculopontine tegmental nuclei (Sakurai et al., 2005). 
The present study only detected very small numbers of input neurons in those areas, suggesting that these cells might be second-order or higher-order input neurons.

Another tracing study of orexin neurons, which used a conventional retrograde tracer in the LHA combined with anterograde tracing to confirm the projections to orexin neurons in rats, also showed similar results to IGFP-TTC tracing (Yoshida et al., 2006). Although labeled neurons were abundant in the BNST and in many hypothalamic regions, including the POA, DMH, LHA, $\mathrm{PH}, \mathrm{PAG}$, and LS, showing similarity to the present study, strong staining was also observed in the allocortex, claustrum, and DRN. In the present study, we could barely detect any input neurons in the DRN (Figs. 2, 3), although our findings suggest that stimulation of DRN fibers evokes direct inhibition of orexin neurons (Fig. 5).

\section{Input to hypothalamic arousal neurons}

In this study, we initially focused on HDC neurons, which produce histamine and play highly important roles in wakefulness regulation. We identified many input cells in a variety of brain regions both inside and outside the hypothalamus (Fig. 1). POA regions showed enormous numbers of input cells and many of them were GABAergic (Fig. 4), suggesting that HDC neurons are regulated by GABAergic input from the POA. This is consistent with a previous study showing that optogenetic activation of axons of POA GABAergic neurons projecting into the TMN caused an immediate increase in NREM sleep and a delayed increase in REM sleep, which was partly mediated by reduced histamine release (Chung et al., 2017). Our present study further confirmed direct synaptic connectivity between $\mathrm{GABA}^{\mathrm{POA}}$ neurons and HDC neurons (Fig. 4).

Other hypothalamic regions, including the LHA, also contained many labeled input cells. Some populations of input cells expressed orexin, consistent with previous reports showing that orexin neurons send a rich projection to the TMN, where extensive expression of $\mathrm{OX} 2 \mathrm{R}$, a receptor critically implicated in the regulation of arousal, is observed (Mieda et al., 2011).

We also further mapped input neurons of orexin and found that the distribution pattern of input neurons of orexin neurons was very similar to that of HDC neurons (Figs. 1,2). This suggests that upstream brain regions control orexin neurons and HDC neurons in parallel. It was reported that concomitant photostimulation of orexin neurons and NA neurons increased the probability of sleep-to-wake transitions significantly compared with orexin neuron stimulation alone (Carter et al., 2012). Considering the close functional relationship between orexin neurons and HDC neurons, similar to that between orexin neurons and NA neurons, simultaneous excitation of these neurons might also have relevance in physiological functions. Our observation that orexin neurons and HDC neurons receive similar input might suggest that these neuronal populations are concomitantly regulated by similar upstream brain regions to regulate arousal more efficiently. Consistently, our anterograde tracing study suggested that a population of VLPO GABA neurons sends collateral projections to both orexin and HDC neurons (Fig. 4H)

However, we simultaneously found several differences in the distribution of input neurons of orexin and HDC neurons. The proportions of input neurons in the PVN, NAC, and BNST were smaller for HDC neurons compared with orexin neurons (Fig. 3). We repeatedly failed to detect input neurons of orexin neurons in the cortex, whereas we detected input neurons of HDC neurons in the frontal cortices (Figs. 1,3). This suggests that HDC neurons tend to be controlled by higher-order neurons compared with orexin neurons.

Our present study identified a substantial number of input neurons in the NAC and BNST in both orexin and HDC neuron tracings. However, although we found positive neurons in regions implicated in reward and emotion, most of these neurons were GABAergic inhibitory neurons, so direct input by NAC or BNST GABAergic neurons rather inhibits orexin neurons. Given that many reports showed that activation or disinhibition of BNST results in activation of orexin neurons (Zhang et al., 2009; Kodani et al., 2017) and orexin neurons are activated upon perception of reward (e.g., food; González et al., 2016b), although some populations of GABAergic neurons in the BNST and NAC send direct inhibitory input to orexin neurons, these neurons might send collateral innervation to other GABAergic neurons that send input to orexin or histamine neurons. Alternatively, other populations of GABAergic neurons in the NAC and BNST may indirectly activate orexin neurons through inhibition of GABAergic neurons that make direct contact with orexin and HDC neurons.

\section{Monoaminergic regulation of GABA ${ }^{\mathrm{VLPO}}$ neurons that send direct synaptic input to orexin neurons and histaminergic neurons}

Our previous studies showed that NA and 5-HT inhibit orexin neurons directly (Muraki et al., 2004; Yamanaka et al., 2006). However, we also found that NA increases sIPSC frequency and amplitude via $\alpha 1$ adrenergic receptors in GABAergic neurons that innervate orexin neurons. The present study further identified the pathway by which NA and 5-HT disinhibit orexin neurons: through inhibition of GABA ${ }^{\mathrm{VLPO} \rightarrow \text { orexin }}$ neurons. These observations suggest that monoamines influence the activity of orexin neurons in a complex manner.

It has been shown that there are two types of GABA ${ }^{\mathrm{VLPO}}$ neurons. One type are the sleep-promoting projection neurons that send inhibitory projections to arousal centers and the other is local interneurons that rather inhibit sleep-promoting cells (Gallopin et al., 2000; Liu et al., 2010). One of the criteria that can distinguish these neurons is their responsiveness to NA. Projection neurons are inhibited by NA, whereas local GABAergic interneurons are activated by NA. We found that most $\mathrm{GABA}^{\mathrm{VLPO} \rightarrow \text { orexin }}$ and GABA ${ }^{\mathrm{VLPO} \rightarrow \mathrm{HDC}}$ neurons are potently inhibited by NA and 5-HT. No cell was found to be activated by NA. These observations suggest the possibility that sleeppromoting projection neurons in the VLPO send direct input to orexin and histaminergic neurons and these arousalpromoting hypothalamic neurons are disinhibited by NA and 5-HT. However, optogenetic excitation of 5-HT fibers in the LHA rather inhibits orexin neurons (Fig. 5). DREADDmediated excitation of $5-\mathrm{HT}^{\mathrm{DRN}}$ neurons showed minimal effect on activity of orexin neurons (Fig. $5 G-I$ ). These observations suggest that the $5-\mathrm{HT}^{\mathrm{DRN}} \rightarrow \mathrm{GABA}^{\mathrm{VLPO}} \rightarrow$ orexin pathway might counteract the inhibitory effect of the direct 5 -HT ${ }^{\text {DRN }} \rightarrow$ orexin pathway, which might play a role in negative feedback regulation.

\section{Conclusion}

In the present study, we compared the tissue distribution patterns of neurons that send direct innervations to HDC and orexin neurons and found that these two populations receive a very similar distribution of input neurons, suggesting that similar higher input controls these populations. Both neuronal populations were heavily innervated by GABAergic neurons in the POA, including the VLPO. We 
also found that GABA ${ }^{\mathrm{VLPO} \rightarrow \mathrm{HDC}}$ and GABA ${ }^{\mathrm{VLPO} \rightarrow \text { orexin }}$ neurons are inhibited by NA and 5-HT, suggesting that these neurons are sleep-active neurons. This work shows close functional and structural interactions between GABA ${ }^{\mathrm{VLPO}}$ neurons and hypothalamic arousal neurons and the influence of monoamines on these circuits (Fig. 6).

\section{References}

Agnati LF, Zoli M, Strömberg I, Fuxe K (1995) Intercellular communication in the brain: wiring versus volume transmission. Neuroscience 69:711726. CrossRef Medline

Atasoy D, Aponte Y, Su HH, Sternson SM (2008) A FLEX switch targets channelrhodopsin-2 to multiple cell types for imaging and long-range circuit mapping. J Neurosci 28:7025-7030. CrossRef Medline

Borbély AA (1982) A two process model of sleep regulation. Hum Neurobiol 1:195-204. Medline

Carter ME, Brill J, Bonnavion P, Huguenard JR, Huerta R, de Lecea L (2012) Mechanism for hypocretin-mediated sleep-to-wake transitions. Proc Natl Acad Sci U S A 109:E2635-E2644. CrossRef Medline

Chou TC, Bjorkum AA, Gaus SE, Lu J, Scammell TE, Saper CB (2002) Afferents to the ventrolateral preoptic nucleus. J Neurosci 22:977-990. CrossRef Medline

Chung S, Weber F, Zhong P, Tan CL, Nguyen TN, Beier KT, Hörmann N, Chang WC, Zhang Z, Do JP, Yao S, Krashes MJ, Tasic B, Cetin A, Zeng H, Knight ZA, Luo L, Dan Y (2017) Identification of preoptic sleep neurons using retrograde labelling and gene profiling. Nature 545:477-481. CrossRef Medline

Date Y, Mondal MS, Matsukura S, Ueta Y, Yamashita H, Kaiya H, Kangawa K, Nakazato M (2000) Distribution of orexin/hypocretin in the rat median eminence and pituitary. Brain Res Mol Brain Res 76:1-6. CrossRef Medline

Ericson H, Watanabe T, Köhler C (1987) Morphological analysis of the tuberomammillary nucleus in the rat brain: delineation of subgroups with antibody against L-histidine decarboxylase as a marker. J Comp Neurol 263:1-24. CrossRef Medline

Franklin KBJ, Paxinos G (2001) The mouse brain in stereotaxic coordinates. San Diego, CA: Academic.

Gallopin T, Fort P, Eggermann E, Cauli B, Luppi PH, Rossier J, Audinat E, Mühlethaler M, Serafin M (2000) Identification of sleep-promoting neurons in vitro. Nature 404:992-995. CrossRef Medline

Gallopin T, Luppi PH, Cauli B, Urade Y, Rossier J, Hayaishi O, Lambolez B, Fort $\mathrm{P}$ (2005) The endogenous somnogen adenosine excites a subset of sleep-promoting neurons via $\mathrm{A} 2 \mathrm{~A}$ receptors in the ventrolateral preoptic nucleus. J Neurosci 134:1377-1390. CrossRef Medline

Gong S, Zheng C, Doughty ML, Losos K, Didkovsky N, Schambra UB, Nowak NJ, Joyner A, Leblanc G, Hatten ME, Heintz N (2003) A gene expression atlas of the central nervous system based on bacterial artificial chromosomes. Nature 425:917-925. CrossRef Medline

González JA, Iordanidou P, Strom M, Adamantidis A, Burdakov D (2016a) Awake dynamics and brain-wide direct inputs of hypothalamic $\mathrm{MCH}$ and orexin networks. Nat Commun 7:11395. CrossRef Medline

González JA, Jensen LT, Iordanidou P, Strom M, Fugger L, Burdakov D (2016b) Inhibitory interplay between orexin neurons and eating. Curr Biol 26:2486-2491. CrossRef Medline

Inagaki N, Toda K, Taniuchi I, Panula P, Yamatodani A, Tohyama M, Watanabe T, Wada $\mathrm{H}$ (1990) An analysis of histaminergic efferents of the tuberomammillary nucleus to the medial preoptic area and inferior colliculus of the rat. Exp Brain Res 80:374-380. Medline

Kodani S, Soya S, Sakurai T (2017) Excitation of GABAergic neurons in the bed nucleus of the stria terminalis triggers immediate transition from non-rapid eye movement sleep to wakefulness in mice. J Neurosci 37: 7164-7176. CrossRef Medline

Liu YW, Li J, Ye JH (2010) Histamine regulates activities of neurons in the ventrolateral preoptic nucleus. J Physiol 588:4103-4116. CrossRef Medline

Lu J, Greco MA, Shiromani P, Saper CB (2000) Effect of lesions of the ventrolateral preoptic nucleus on NREM and REM sleep. J Neurosci 20: 3830-3842. CrossRef Medline

Maskos U, Kissa K, St Cloment C, Brûlet P (2002) Retrograde trans-synaptic transfer of green fluorescent protein allows the genetic mapping of neuronal circuits in transgenic mice. Proc Natl Acad Sci U S A 99:1012010125. CrossRef Medline
Matsuki T, Nomiyama M, Takahira H, Hirashima N, Kunita S, Takahashi S, Yagami K, Kilduff TS, Bettler B, Yanagisawa M, Sakurai T (2009) Selective loss of $\mathrm{GABA}(\mathrm{B})$ receptors in orexin-producing neurons results in disrupted sleep/wakefulness architecture. Proc Natl Acad Sci U S A 106: 4459-4464. CrossRef Medline

Mieda M, Hasegawa E, Kisanuki YY, Sinton CM, Yanagisawa M, Sakurai T (2011) Differential roles of orexin receptor-1 and -2 in the regulation of non-REM and REM sleep. J Neurosci 31:6518-6526. CrossRef Medline

Miyamichi K, Amat F, Moussavi F, Wang C, Wickersham I, Wall NR, Taniguchi H, Tasic B, Huang ZJ, He Z, Callaway EM, Horowitz MA, Luo L (2011) Cortical representations of olfactory input by trans-synaptic tracing. Nature 472:191-196. CrossRef

Moriwaki C, Chiba S, Wei H, Aosa T, Kitamura H, Ina K, Shibata H, Fujikura Y (2015) Distribution of histaminergic neuronal cluster in the rat and mouse hypothalamus. J Chem Neuroanat 68:1-13. CrossRef Medline

Moore JT, Chen J, Han B, Meng QC, Veasey SC, Beck SG, Kelz MB (2012) Direct activation of sleep-promoting VLPO neurons by volatile anesthetics contributes to anesthetic hypnosis. Curr Biol 22:2008-2016. CrossRef

Muraki Y, Yamanaka A, Tsujino N, Kilduff TS, Goto K, Sakurai T (2004) Serotonergic regulation of the orexin/hypocretin neurons through the 5-HT1A receptor. J Neurosci 24:7159-7166. CrossRef Medline

Nambu T, Sakurai T, Mizukami K, Hosoya Y, Yanagisawa M, Goto K (1999) Distribution of orexin neurons in the adult rat brain. Brain Res 827:243260. CrossRef Medline

Osakada F, Callaway EM (2013) Design and generation of recombinant rabies virus vectors. Nat Protoc 8:1583-1601. CrossRef Medline

Saito YC, Tsujino N, Hasegawa E, Akashi K, Abe M, Mieda M, Sakimura K, Sakurai $T$ (2013) GABAergic neurons in the preoptic area send direct inhibitory projections to orexin neurons. Front Neural Circuits 7:192. CrossRef Medline

Sakai K, Takahashi K, Anaclet C, Lin JS (2010) Sleep-waking discharge of ventral tuberomammillary neurons in wild-type and histidine decarboxylase knock-out mice. Front Behav Neurosci 4:53. CrossRef Medline

Sakurai T, Nagata R, Yamanaka A, Kawamura H, Tsujino N, Muraki Y, Kageyama H, Kunita S, Takahashi S, Goto K, Koyama Y, Shioda S, Yanagisawa M (2005) Input of orexin/hypocretin neurons revealed by a genetically encoded tracer in mice. Neuron 46:297-308. CrossRef Medline

Saper CB, Fuller PM, Pedersen NP, Lu J, Scammell TE (2010) Sleep state switching. Neuron 68:1023-1042. CrossRef Medline

Sasaki K, Suzuki M, Mieda M, Tsujino N, Roth B, Sakurai T (2011) Pharmacogenetic modulation of orexin neurons alters sleep/wakefulness states in mice. PLoS One 6:e20360. CrossRef Medline

Sherin JE, Shiromani PJ, McCarley RW, Saper CB (1996) Activation of ventrolateral preoptic neurons during sleep. Science 271:216-219. CrossRef Medline

Sherin JE, Elmquist JK, Torrealba F, Saper CB (1998) Innervation of histaminergic tuberomammillary neurons by GABAergic and galaninergic neurons in the ventrolateral preoptic nucleus of the rat. J Neurosci 18: 4705-4721. CrossRef Medline

Steininger TL, Gong H, McGinty D, Szymusiak R (2001) Subregional organization of preoptic area/anterior hypothalamic projections to arousalrelated monoaminergic cell groups. J Comp Neurol 429:638-653. CrossRef Medline

Tamamaki N, Yanagawa Y, Tomioka R, Miyazaki J, Obata K, Kaneko T (2003) Green fluorescent protein expression and colocalization with calretinin, parvalbumin, and somatostatin in the GAD67-GFP knock-in mouse. J Comp Neurol 467:60-79. CrossRef Medline

Tsunematsu T, Fu LY, Yamanaka A, Ichiki K, Tanoue A, Sakurai T, van den Pol AN (2008) Vasopressin increases locomotion through a V1a receptor in orexin/hypocretin neurons: implications for water homeostasis. J Neurosci 28:228-238. CrossRef Medline

Umehara H, Mizuguchi H, Fukui H (2012) Identification of a histaminergic circuit in the caudal hypothalamus: an evidence for functional heterogeneity of histaminergic neurons. Neurochem Int 61:942-947. CrossRef Medline

Varin C, Rancillac A, Geoffroy H, Arthaud S, Fort P, Gallopin T (2015) Glucose induces slow-wave sleep by exciting the sleep-promoting neurons in the ventrolateral preoptic nucleus: A new link between sleep and metabolism. J Neurosci 8:35:9900-9911. CrossRef 
Wall NR, Wickersham IR, Cetin A, De La Parra M, Callaway EM (2010). Monosynaptic circuit tracing in vivo through Cre-dependent targeting and complementation of modified rabies virus. Proc Natl Acad Sci 14:107: 21848-21853. CrossRef

Watabe-Uchida M, Zhu L, Ogawa SK, Vamanrao A, Uchida N (2012) Whole-brain mapping of direct inputs to midbrain dopamine neurons. Neuron 74:858-873. CrossRef Medline

Wickersham IR, Finke S, Conzelmann KK, Callaway EM (2007) Retrograde neuronal tracing with a deletion-mutant rabies virus. Nat Methods 4:4749. CrossRef Medline

Winsky-Sommerer R, Yamanaka A, Diano S, Borok E, Roberts AJ, Sakurai T, Kilduff TS, Horvath TL, de Lecea L (2004) Interaction between the corticotropin-releasing factor system and hypocretins (orexins): a novel circuit mediating stress response. J Neurosci 24:11439-11448. CrossRef Medline

Wu S, Esumi S, Watanabe K, Chen J, Nakamura KC, Nakamura K, Kometani K, Minato N, Yanagawa Y, Akashi K, Sakimura K, Kaneko T, Tamamaki N (2011) Tangential migration and proliferation of intermediate progenitors of GABAergic neurons in the mouse telencephalon. Development 138:2499-2509. CrossRef Medline
Yamanaka A, Beuckmann CT, Willie JT, Hara J, Tsujino N, Mieda M, Tominaga M, Yagami Ki, Sugiyama F, Goto K, Yanagisawa M, Sakurai T (2003) Hypothalamic orexin neurons regulate arousal according to energy balance in mice. Neuron 38:701-713. CrossRef Medline

Yamanaka A, Muraki Y, Ichiki K, Tsujino N, Kilduff TS, Goto K, Sakurai T (2006) Orexin neurons are directly and indirectly regulated by catecholamines in a complex manner. J Neurophysiol 96:284-298. CrossRef Medline

Yoshida K, McCormack S, España RA, Crocker A, Scammell TE (2006) Afferents to the orexin neurons of the rat brain. J Comp Neurol 494:845861. CrossRef Medline

Yu X, Ye Z, Houston CM, Zecharia AY, Ma Y, Zhang Z, Uygun DS, Parker S, Vyssotski AL, Yustos R, Franks NP, Brickley SG, Wisden W (2015) Wakefulness is governed by GABA and histamine cotransmission. Neuron 87:164-178. CrossRef Medline

Zhang W, Zhang N, Sakurai T, Kuwaki T (2009) Orexin neurons in the hypothalamus mediate cardiorespiratory responses induced by disinhibition of the amygdala and bed nucleus of the stria terminalis. Brain Res 1262:25-37. CrossRef Medline 